\title{
AMYOTROPHIC LATERAL SCLEROSIS (ALS)
}

\section{THREE LETTERS THAT CHANGE THE PEOPLE'S LIFE}

\section{For ever}

\author{
Acary Souza Bulle Oliveira', Roberto Dias Batista Pereira ${ }^{2}$
}

\begin{abstract}
Amyotrophic lateral sclerosis (ALS) is a neurodegenerative disease affecting the motor nervous system. It causes progressive and cumulative physical disabilities in patients, and leads to eventual death due to respiratory muscle failure. The disease is diverse in its presentation, course, and progression. We do not yet fully understand the cause or causes of the disease, nor the mechanisms for its progression; thus, we lack effective means for treating this disease. Currently, we rely on a multidisciplinary approach to symptomatically manage and care for patients who have ALS. Although amyotrophic lateral sclerosis and its variants are readily recognized by neurologists, about $10 \%$ of patients are misdiagnosed, and delays in diagnosis are common. Prompt diagnosis, sensitive communication of the diagnosis, the involvement of the patient and their family, and a positive care plan are prerequisites for good clinical management. A multidisciplinary, palliative approach can prolong survival and maintain quality of life. Treatment with Riluzole improves survival but has a marginal effect on the rate of functional deterioration, whereas non-invasive ventilation prolongs survival and improves or maintains quality of life. In this Review, we discuss the diagnosis, management, and how to cope with impaired function and end of life on the basis of our experience, the opinions of experts, existing guidelines, and clinical trials. Multiple problems require a multidisciplinary approach including aggressive symptomatic management, rehabilitation to maintain motor function, nutritional support (enteric feeding, gastrostomy), respiratory support (non invasive home ventilation, invasive ventilation, tracheotomy), augmentative communication devices, palliative care, psychological support for both patients and families (because family members so often play a central role in management and care), communication between the care team, the patient and his or her family, and recognition of the clinical and social effects of cognitive impairment. Social, bioethical, and financial issues as well as advance directives should be addressed. A plethora of evidence-based guidelines should be compiled into an internationally agreed guideline of best practice. The multidisciplinary team has changed the history of disease, with still no curative therapy available.
\end{abstract}

KEY WORDS: amyotrophic lateral sclerosis, diagnosis, treatment.

\section{Esclerose lateral amiotrófica (ELA): três letras que mudam a vida de uma pessoa. Para sempre.}

Resumo - A esclerose lateral amiotrófica (ELA) é doença neurodegenerativa comprometendo o sistema nervoso motor. Ela causa comprometimento físico, progressivo e acumulativo, com óbito freqüentemente decorrente de falência respiratória. A enfermidade apresenta características diversas nas formas de apresentação, curso e progressão. Não entendemos ainda a causa ou causas dessa enfermidade, nem os mecanismos que regem a sua progressão; assim, tratamentos efetivos não são, até o momento, conhecidos. Atualmente, recomenda-se que os pacientes com ELA sejam tratados com equipe multidisciplinar. Embora ELA e suas variantes sejam reconhecidas por neurologistas, cerca de $10 \%$ dos pacientes são mal diagnosticados, $\mathrm{e}$ a demora para a confirmação diagnóstica não é incomum. Diagnóstico precoce, informação do diagnóstico com honestidade e sensibilidade, envolvimento do paciente e sua familia, e um plano de atenção terapêutica positivo são pré-requisitos essenciais para um melhor resultado clínico e fim terapêutico. Tratamento

\footnotetext{
Universidade Federal de São Paulo/Escola Paulista de Medicina, São Paulo SP, Brazil (UNIFESP/EPM) / Associação Brasileira de Esclerose Lateral Amiotrófica (ABRELA): 'Professor Afiliado, Departamento de Neurologia, UNIFESP/EPM; ${ }^{2}$ Pós-Graduando do Departamento de Neurologia, UNIFESP/EPM; Diretor Científico da ABRELA.
} 
multidisciplinar e cuidados paliativos podem prolongar a sobrevida e manter melhores aspectos de qualidade de vida. Tratamento com Riluzol aumenta a sobrevida, mas sem alteração na deterioração funcional, enquanto que ventilação não-invasiva prolonga a sobrevida e aumenta ou mantém qualidade de vida. Nesta revisão, nós discutimos o diagnóstico, envolvimento e formas de lidar com dificuldades de funcionamento e de fim de vida, baseando-se na nossa experiência, nos pareceres de peritos, em guias de medicina baseada em evidências científicas, e nos ensaios clínicos. Problemas múltiplos exigem uma abordagem multidisciplinar, incluindo-se tratamento sintomático agressivo, reabilitação para manter a função motora, apoio nutricional (alimentação entérica, gastrostomia), suporte respiratório (ventilação domiciliar não-invasiva, ventilação invasiva, traqueostomia), dispositivo para comunicação aumentativa, cuidados paliativos, apoio psicológico para ambos, pacientes e familiares (uma vez que os familiares, muitas vezes, desempenham um papel central na gestão e no atendimento), a comunicação entre equipe multidisciplinar, o paciente e sua família, bem como o reconhecimento da clínica e os efeitos sociais do declínio cognitivo. Questões sociais, financeiras e de bioética também devem ser consideradas. A multiplicidade de orientações com base em guias de consensos de melhor prática clínica devem ser fornecidas para os pacientes com ELA. As orientações multidisciplinares têm mudado a história desta doença, ainda com nenhuma terapia curativa disponivel.

PALAVRAS-CHAVE: esclerose lateral amiotrófica, diagnóstico, tratamento.

Amyotrophic lateral sclerosis (ALS) is a devastating neurodegenerative disorder that results in the selective death of motor neurons in the central nervous system. This progressive motor neuron degeneration leads to death of the patient on average three to five years after onset of the disease.

The unique clinical signs and symptoms and patterns of progression not shared by other diseases causes a profound effect upon the individual with ALS and her or his family. The stress incurred from living with illness is a consequence of the: disease-mitigated changes in physical and psychosocial functionin; the individual's internal conditioning factors; no available curative therapy; financial burden; end-of-life issues; death representing the main hallmark.

Charcot named ALS over one hundred years ago, but it is only in the last 25 years that we have gained a better understanding of the disease, its treatment and the care of ALS/MND patients. In the pursuit of early diagnosis and, thus, early treatment with disease specific agents such as Riluzole, the World Federation of Neurology, has reached an International Consensus on the diagnostic definition of ALS and they have developed criteria for the conduct of clinical trials in ALS.

Supportive care was almost non-existent until the 1970s. Today, clinical care is aimed both at prolonging life and improving quality of life. The multidisciplinary team has changed the history of this disease.

\section{QUESTION OF TERMINOLOGY}

Diseases that affect motor neurons can be classified as primary, secondary, or multisystem. The terms "motor neuron diseases" and "motor neuron disorders" are used to refer to any disease affecting motor neurons".
The specific term "Motor Neuron Disease" (MND) is used in Europe as progressive neurodegenerative disorders with different etiologist and clinical variability, but a common final event: loss of upper and / or lower motor neurons. Depending on which motor neurons are affected, there are four main forms identified, but they may overlap: (1) Primary lateral sclerosis (PLS) is a condition in which upper motor neuron signs occur in the absence of lower motor neuron signs, and pathologic changes are restricted to the motor cortex and corticospinal tracts. It is characterized by spasticity, hipereflexia, Babinski's signal. It represents the least common form of MND, affecting less those $2 \%$ of all cases; (2) Progressive muscular atrophy (PMA) is a condition in which lower motor neuron signs correlating with a loss of anterior horn cells occur in the absence of upper motor neurons signs, and in which the motor neurons signs are preserved. It is characterized by muscle weakness and wasting, weight loss and fasciculation. It represents around $5 \%$ of all MND cases; (3) Progressive bulbar palsy (PBP), affecting the muscles of the bulbar region, is characterized by dysarthria, dysphagia, tongue atrophy, and fasciculation. Approximately $20 \%$ of patients who later develop other features of ALS present initially with PBP; (4) Amyotrophic lateral sclerosis is the most frequent MND's presentation, having its name as MND synonymous (ALS / MND). It is characterized by a progressive degeneration of lower and upper motor neurons in the cerebral cortex, brainstem, and spinal cord, resulting in muscular atrophy, fasciculation's, weakness and spasticity.

\section{HISTORY AND RECOGNITION OF ALS / MND}

By the 1830s, the condition of progressive muscular atrophy (today called spinal muscular atrophy or SMA) was commonly recognized, although it was not named until 
1848 or 1850. Descriptions of SMA and PBP were added to the literature between 1859 and 1870 . However, a landmark series of lectures was given by Jean-Martin Charcot at the Salpêtrière in Paris, in 1874. The lectures were drawn from 20 clinical cases and five autopsies. It was here that Charcot and Joffroy combined the clinical observations of 1) atrophic muscular weakness (amyotrophy) and spasticity with 2) pathological findings, hardening of the lateral columns of the spinal cord (lateral sclerosis) and lesions of the anterior horn. Charcot named the progressive disorder "de la sclérose laterale amyotrophique" (amyotrophic lateral s clerosis or ALS).

One hundred years of relative silence followed Charcot's naming of ALS/MND. Patients were diagnosed but not treated. They were told to go home and "put your affairs in order", nothing could be done so "there is no need to make a return appointment to the clinic". The U.S. was revisited in 1941 by the death due to ALS of the famous 37-year-old New York baseball player, Lou Gehrig. Henceforth in the U.S., ALS was commonly called Lou Gehrig's disease. Interestingly, Mr Gehrig received experimental injections of vitamin $E$ through a research study conducted by the Mayo Clinic ${ }^{2}$.

In the 1950s, new forms of the disease were recognized in the form of familial and Guamanian ALS/MND.

1969 began an awakening of interest in ALS with the publication of papers delivered at an International Symposium devoted in Motor Neuron Disease. New techniques were advanced to diagnose ALS, including electromyography (EMG). New theories of the possible aetiology of ALS were put forward, based on more complete understanding of neurotransmitters in the motor system. Although publications remained sparse throughout the 1970s, there was an explosion in the late $1980 s^{3}$ (Timeline).

\section{DIAGNOSIS}

The onset and early progression of ALS is frequently insidious, and symptoms may go unrecognized and undiagnosed for up to 12 months. During the diagnostic evaluation, a patient commonly consults a variety of specialists, and even neurologists may not recognize ALS early in its course. Once ALS is considered, many laboratory tests are completed before the diagnosis is made because it is frequently considered to be a diagnosis of exclusion.

For many years, the only published criteria for the recognition of DNM / ALS was made by Lambert $(1957,1969)^{4}$, established through electromyography. The most important change in diagnosis criteria occurred in 1990. The World Federation of Neurology (WFN), in conjunction with the Spanish fund for Healthy research and the Spanish ALS Association, convened a task force in El Escorial, Spain to establish a set of clinical diagnostic criteria for $A L S^{5}$. The diagnosis of ALS would be defined within the evidence of signs
Timeline.

1830 Bell reports a case of a progressive paralysis of limbs and tongue with preservation of sensation.

1850 Aran names the condition of progressive muscular atrophy (PMA).

1853 Duchenne claims priority over Aran in reporting Spinal Muscular Atrophy (SMA).

1865 Charcot describes Progressive Lateral Sclerosis (PLS).

1870 Charcot describes Progressive Bulbar palsy (PBP).

1874 Charcot names ALS (de la sclérose laterále amyotrophique).

1883 PBP and ALS united as the same syndrome.

1899 Gowers considers that ALS and PBP are caused by motor neuron degeneration.

1900 Guam: ALS-like description.

1930 Brain considers that ALS and MND are synonymous.

1939 Lou Gehrig's diagnosis and first clinical trial with vitamin $\mathrm{E}$.

1941 Lou Gehrig dies of ALS.

1943 Vitamin E injections are shown not to be effective to treat ALS.

1950 Levi-Montalcini describes the Nervous Growth Factor.

1952 Hirano describes the Guam ALS/Dementia/Parkinson complex.

1957 Mayo Clinic - first Symposium in ALS/MND

1959 Familial ALS described with posterior column involvement.

1969 Kurland - Norris-I International Symposium on ALS/MND.

1969 Lambert - Diagnostic criteria using Electroneuromyogram (EMG).

1970s EMG formalized as a diagnostic tool.

1972 Amyotrophic Lateral Sclerosis Organization of America (ALSOA) formed.

1973 National Amyotrophic Lateral Sclerosis Foundation (NALSF) formed.

1980 Report of nerve growth factor (NGF) published.

1984 Use of percutaneous endoscopic gastrostomy (PEG) reported in ALS.

1985 Amyotrophic Lateral Sclerosis Association (ALSA) formed as a merger of ALSOA and NALSA.

1987 Glutamate metabolism abnormality reported in ALS.

1989 Motor Neuron Disease Association of the United Kingdom hosts the $1^{\text {st }}$ International Symposium of the International Alliance of ALS/MND Associations.

1993 SOD-1 gene identified.

1994 WFN El Escorial Criteria for diagnosis of ALS published.

1995 First positive clinical trial for ALS. Riluzole has an effect on survival, prolonging life.

1996 National Neuromuscular Nurses Advisory Board is founded.

1996 American Association of Neuroscience nurses forms a special focus group for neuromuscular disease.

1997 American Academy of Neurology forms as special interest group for neuromuscular disease.

1998 WFN Airlie House Criteria for diagnosis of ALS revisited.

1999 American Academy of Neurology publishes an evidencebased ALS Practice Parameter.

2000 Transgenic mouse model of ALS.

$200213^{\text {th }}$ International Symposium on ALS/MND - Letizia Mazzini describes the first treatment with stem cell in ALS patients.

$200819^{\text {th }}$ International Symposium on ALS/MND - Cyanobacteria as a source of BMAA and possible cause of sporadic ALS. 
Table 1. Famous people with ALS.

\begin{tabular}{lccccc}
\hline Name & Born & Profission & Onset & Diagnostic & Death \\
\hline Lou Gehrig & 1903 & Baseball & 1938 & $06 / 1939$ & $06 / 1941$ \\
Ezzard Charles & 1921 & Boxer & 1966 & 1966 & 1975 \\
Bob Waters & 1939 & Football & 1982 & 1985 & 1989 \\
David Niven & 1910 & Actor & 1980 & 1982 & 1983 \\
Charles Mingus & 1922 & Musician & 1976 & 1977 & 1979 \\
Jacob Javits & 1904 & Politic & 1980 & 1980 & 1986 \\
Franz Rosenzweig & 1886 & Filósopher & 1921 & 1922 & 1929 \\
Mao-Tsé-Tung & 1893 & Politic & & & 1976 \\
Stephen Hawking & 1942 & Cientist & 1962 & 1962 & Alive \\
\hline
\end{tabular}

Hawking is obviously an exceptional case and one of very few people to have survived 35 years, already, with the disease.

Table 2. Signs and symptoms of UMN and LMN degeneration.

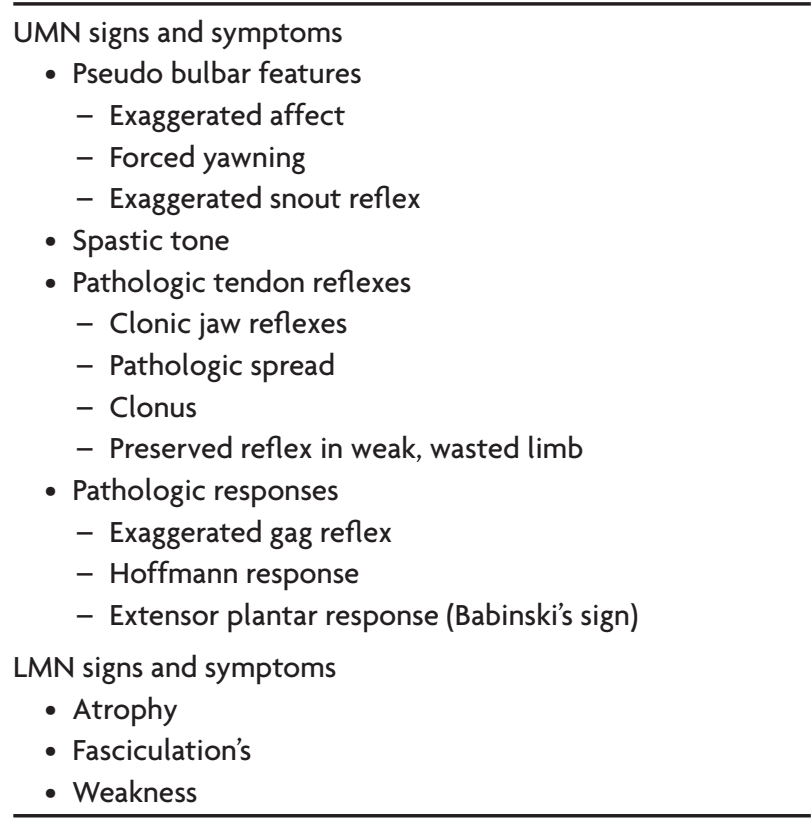

of impairment of lower motor neuron (LMN), through clinical examination, electrophysiological or neuropathologycal changes, associated with impairment of upper motor neuron (UMN) clinically proven, with ongoing chronic and progressive (Table 2 and Table 3). It is still necessary, for diagnosis, the absence of electrophysiological and pathological findings characteristic of other diseases that explain the degeneration of motor neurons, as well as changes in neuroimaging to justify the electrophysiological signals (Table 4).

Clinical diagnosis of ALS has been based on finding evidence of progressive loss of LMN and UMN in a diffuse distribution.

According to the intensity of commitment and clinical meetings electroneuromyographic, the diagnosis of ALS / MND received a sub classification of diagnostic certainty: dfinite ALS, probable ALS, possible ALS and suspected ALS.

Although primarily intended as an algorithm for en-
Table 3. World Federation of Neurology Electrodiagnostic Proposed Criteria for LMN Degeneration.

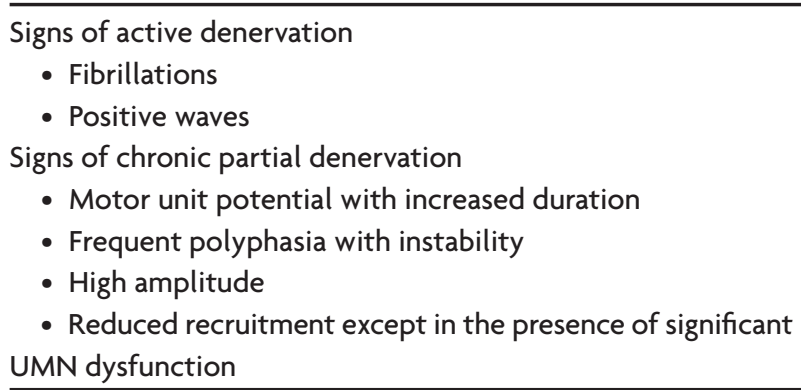

Table 4. World Federation of Neurology (El Escorial) criteria for diagnosis of ALS.

The diagnosis of ALS requires

1) The presence of

- Evidence of LMN degeneration on clinical, electrophysiologic (including EMG features in clinically normal muscles) or neuropathologic examination

- Evidence of UMN degeneration on clinical examination

- Progression of the motor syndrome within a region or to other regions, as determined by history or examination; and

2) The absence of

- Electrophysiological and pathological evidence of other process that might explain the UMN and / or LMN signs; and

- Neuroimaging evidence of other disease processes that might explain the observed clinical and electrophysiological signs

tering patients into clinical studies and therapeutic trials, the El Escorial criteria have been used clinically. There was, however, a consensus among researchers, since certain clinical pictures and, above all, certain electrophysiological findings in some special situations were impossible the completion of diagnosis. The general neurologists and specialists in neuromuscular diseases claimed addition, difficulties with the necessary early ALS diagnosis. 
Table 5. Revised World Federation of Neurology criteria for diagnosis of ALS (EL Escorial revised): categories of diagnostic certainty.

Clinically Definite ALS

- Evidence of UMN plus LMN signs in the bulbar region and in at least two spinal regions, or

- The presence of UMN signs in two spinal regions and LMN signs in three spinal regions

Clinically Probable ALS

- Evidence of UMN plus LMN signs in at least two regions with some UMN signs rostral to LMN signs

Probable, laboratory supported ALS

- Clinical evidence of UMN and LMN signs in only one region, or

- UMN signs alone in one region and LMN signs defined by EMG criteria in at least two muscles of different root and nerve origin in two limbs

Possible ALS

- UMN plus LMN in only one region, or

- UMN signs alone in two or more regions, or

- LMN signs found to rostral to UMN signs

Regions: bulbar, cervical, thoracic and lumbosacral; UMN: upper motor neuron; LMN: lower motor neuron.

Table 6. Clinical features inconsistent with the diagnosis of ALS.

Anterior visual pathway abnormalities

Autonomic nervous system dysfunction

Cognitive abnormalities associated with Alzheimer's disease

Movement abnormalities associated with Parkinson's disease

Sensory disturbance

Sphincter abnormalities

The El Escorial criteria were intended to be reviewed and modified. In May of 1998, in Airlie House (in Warrenton, Virginia, USA), an international group of experienced clinic met to discuss optimal management strategies of ALS and to revise the criteria after 4 years of clinician experience. The reviewed criteria published by the WFN-ALS through the web ${ }^{6}$ has added a level of certainty, "probable ALS - laboratory supported", defined after proper application of neuroimaging and clinical laboratory protocols, excluding other causes. The addition of this category was felt to be necessary to address the early entry of patients into drug trials". The category of "Suspected ALS" (LMN in two or three regions), previously included in the El Escorial Criteria, has been dropped (Table 5).

These criteria may not be useful in diagnosing early ALS. It may be possible that clinical trials in humans for ALS have been mostly unsuccessful because of inclusion of only advanced patients meeting such "tight" criteria. In December 2006, researchers around the globe met in Awaji Island, Japan, to discuss about proposing the new ALS criteria (Awaji criteria) to facilitate detection of ALS in an early stage ${ }^{8}$.

A major issue in accelerating the diagnosis of ALS is the potential for diagnostic inaccuracy. Inaccuracy is due to false-positive and false-negative diagnoses. Even in experienced centers on Neuromuscular Disorders, misdiagnoses are frequently reported ${ }^{9,10}$. Clinical features inconsistent with the ALS diagnosis are presented on Table 6.
For the accuracy of diagnosis are necessary tests for the exclusion of other diagnoses. New methods of electrophysiology, neuroimaging, immunohistochemistry and genome analysis have been added (Table 7).

The exams results should be carefully interpreted (Table 8).

Magnetic resonance imaging (MRI) using a spin echo magnetization transfer sequence (T1 SE / MT MRI) has been shown to be a valuable method of diagnosis. The findings of a bilateral symmetrical hyper intensity of the pyramidal tract are suggestive of ALS denoting degeneration of corticospinal tracts ${ }^{11,12}$.

Considering the clinical and laboratory findings, the motor neuron diseases have been classified as ALS / DNM (sporadic cases, family or genetically determined), ALS plus syndromes (multisystem neurodegenerative disease affecting motor neurons), the ALS - related syndromes (represent symptomatic or secondary forms of motor neuron disease, with a known associated condition that may be causing the disease) and the ALS - variants (are uncommon unless the patient lives in particular geographic locations) (Table 9) ${ }^{13,14}$.

\section{EPIDEMIOLOGICAL AND OVERRAL DEMOGRAPHY}

The reported incidence varies from 0.2 to 2.5 cases per 100,000 per year. Although estimates vary between countries, globally, the overall rate is approximately 2 per $100,000^{15,16}$. This is similar to that estimated for multiple sclerosis (MS) but, because ALS patients die faster, the prevalence of ALS (approximately $7 / 100,000$ ) is lower than that for MS.

A high prevalence of ALS is reported in certain geographical areas, for example the Pacific island of Guam (50 times that of ALS in western countries), leading to speculation about environmental and genetic factors as potential triggers for ALS.

Differences in incidence and prevalence estimates between countries probably reflect a combination of avail- 
Table 7. Clinical laboratory tests frequently ordered in the evaluation of ALS.

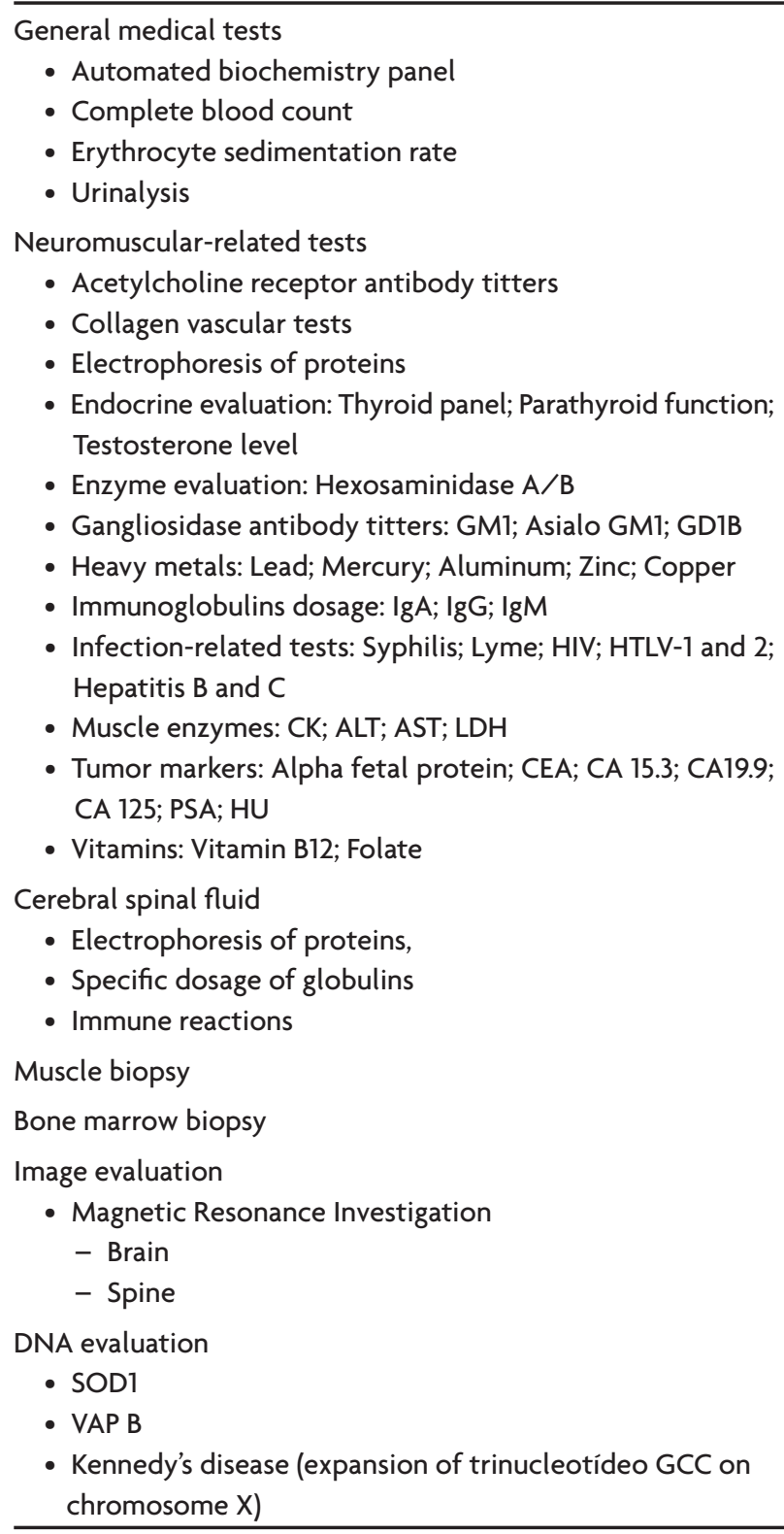

ALS: amyotrophic lateral sclerosis; ALT: alanine aminotransferase; AST: aspartate aminotransferase; CEA: carcino embryonic antigen; CK: creatine kinase; LDH: lactate dehydrogenase; PSA: prostate specific antigen; VDRL: Venereal Disease Research Laboratory.

ability of medical services, diagnostic accuracy and demography characteristics of the area.

The findings relating to the European subgroup study (Italy, Spain, Germany) represents a similar clinical characteristics of ALS in other industrial countries ${ }^{17}$ : a normal age distribution at first presentation with peak at ages 50 59 years ( $26 \%$ of patients) and $60-69$ years ( $27 \%$ of patients). About $13 \%$ of patients were younger than 40 years, and only $1 \%$ older than 79 years. About $39 \%$ of the patients were women. About $82 \%$ of patients presented with limb onset and the remaining $18 \%$ with bulbar onset.
Table 8. Interpretation of the laboratory investigation.

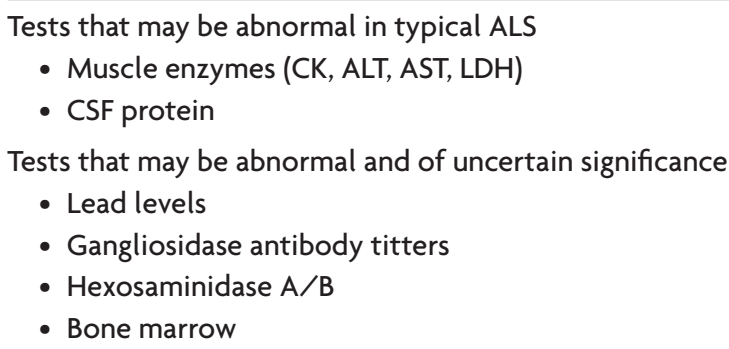

\section{Time to confirmation of diagnosis}

The mean time between first symptoms and first consultation with a physician was 4.9 months and with a neurologist was 6 months. This resulted in a mean time from symptom onset to confirmation of diagnosis of 17.8 months. Many ALS patients are not diagnosed until a later stage of the disease. There was little difference in the speed of diagnosis between ALS with bulbar or limb onset. The diagnosis was confirmed earlier if fasciculations were an early and prominent sign.

The long delay from the symptom onset to diagnosis of ALS was due to uncertainty about the significance of early symptoms and the wide differential diagnosis of early disability in ALS.

\section{FAMILIAL ALS}

Most cases of ALS appear sporadically but some forms of the disease result from mutations in the gene encoding the antioxidant enzyme $\mathrm{Cu} / \mathrm{Zn}$ super oxide dismutase (SOD1). Several other mutated genes have also been found to predispose to ALS including, among others, one that encodes the regulator of axonal retrograde transport dynactin.

A genetic risk factor accounts for $5-10 \%$ of all ALS cases and mutation in the copper/zinc super oxide dismutase 1 (SOD-1) gene have been detected in approximately $20 \%$ of these cases ( $2-3 \%$ total patients) $)^{18,19}$. Since 1993, 139 mutations have been found in the SOD1 gene on chromosome 21 with five different modes of inheritance: dominant inheritance with high penetrance, dominant inheritance with reduced penetrance, recessive inheritance, compound heterozygosity and a de novo mutation. The most frequent SOD1 gene mutation is the D90A which in many European countries is inherited as a recessive trait with a characteristic slowly progressing phenotype though pedigrees with dominantly inherited D90ASOD1 and an aggressive phenotype have also been reported. The most frequent mutation in North America is the A4V which is associated with a very aggressive form of ALS. In different populations, $12 \%$ to $23 \%$ of patients diagnosed with familial ALS (FALS) and 2 to $7 \%$ of Sporad- 
Table 9. Disorders affecting motor neurons.

Primary motor neuron disorders

- Idiopatic

- Motor Neuron Disease: ALS and variants

- Monomelic Motor Neuron Disease: Hirayama

- Inherited

- Autosomal recessive

- Spinal Muscular Atrophy: Type I, Type II and Type III

- Neuro axonal dystrophy

- Hereditary bulbar palsy (HBP) (Fazio-Londe disease)

- HBP with deafness (Brown-Violetta-van Laere Syndrome)

- Juvenile onset ALS

- X-linked

- X-linked bulbospinal neuronopathy (Kennedy's disease)

- Autosomal dominant

- Familial ALS

Secondary motor neuron disorders

- ALS-related syndromes

- Environmental

- Lead, Arsenic, Mercury, Aluminium, Cadmium, Thallium

- Neurolathirism

- Konzo

- Immune

- Paraproteinemia

- Dysimmune motor system degeneration, with anti-GM1 antibody

- Infective

- Acute poliomyelitis

- HIV infection

- Human T-cell leukaemia/lymphoma virus (HTLV-1) infection

- Syphilis

- Borreliosis

- Prion disease

- Metabolic

- Enzyme defects: hexosaminidase A deficiency

- Endocrine: Hyperparathyroidism; hypothyroidism

- Physical injury

- Radiation therapy

- Post-traumatic syringomyelia

- Postinfectious

- Post-polio syndrome

- Tumors

- Hodgkin's disease

- Non-Hodgkin's lymphoma

- ALS plus syndrome (multisystem neurodegenerative disease affecting motor neurons)

- Geographic variants

- ALS-parkinsonism-dementia complex (Western Pacific, Guam, Kii Peninsula)

- ALS and fronto-temporal dementia

- Spino cerebellar degeneration

- Machado-Joseph disease

- Olivopontocerebellar atrophy

- ALS and parkinsonism

- ALS and multisystem degeneration

- Shy-Dragger Syndrome

- Progressive supranuclear palsy

- Huntington's disease

- Neuroacanthocytosis

- Prion disease ic ALS (SALS) patients carry a SOD1 mutation. Diminished disease penetrance is not infrequent for carriers of some SOD1 gene mutations (like the 1113T, G93S, D76Y) and SOD1 mutations can be found in cases of apparently SALS ${ }^{20}$.

Other mutations in other genes have been discovered and implicated in ALS (Table 10) ${ }^{21}$.

The remaining $\sim 80 \%$ of familial cases are linked to as yet unknown genes. Sporadic ALS may possibly be linked to alterations in more complex gene systems, forming genetic risks factors rather than a direct cause of ALS.

\section{Vesicle-trafficking protein VAPB}

Recently a mutation in the gene coding for the protein VAPB (vesicle-associated membrane protein-associated protein B), mapped at 20q13.3, was reported in a large white Brazilian family with ALS cases and traced to a common ancestor from the time of contact with Portugal. The study of VAPB and its interactions with other cellular proteins suggests that the mutation may lead to a less stable interaction of this endoplasmic reticulum protein with at least two other proteins: tubulin and GAPDH. These two proteins have been previously related to other forms of neurodegenerative diseases and are potential key points to understand the biology and at which to aim therapeutics. Another involved mechanism is the transport inhibition of mitochondria affecting the regulation of the anterograde motor kinesin- $\mathbf{1}^{22}$.

Identifying different disease subtypes is an unavoidable step toward the understanding of the physiopathology of ALS and will hopefully help to design specific treatments for each subset of patients ${ }^{23}$.

\section{NEUROPATHOLOGY}

\section{Macroscopic appearances}

The anterior nerve roots often appear shrunken and grey when compared with the posterior, sensory roots. The spinal cord may be atrophic. In most instances the brain is macroscopically normal, but in small proportion of cases the precentral gyrus appears atrophic. In patients with dementia the frontal and temporal lobes may be atrophied.

\section{Microscopic appearances}

The most characteristic finding is a loss of motor neurons and astrocytosis in the spinal cord, brain stem, and motor cortex. The remaining motor neurons in the spinal cord and brain stem may show cytoskeletal abnormalities.

Inclusion bodies may be seen in sections stained with haematoxylin and eosin, but the distinct inclusions are more readily visualized by immunostaining for ubiquitin. Inclusions are seen in both sporadic and familial ALS.

Spinal motor neurons may be ballooned due to an accumulation of phosphorylated neurofilaments, but this is a non-specific finding ${ }^{24}$. 
Table 10. Loci / genes identified in familial ALS / MND.

\begin{tabular}{lccc}
\hline Disease & Inheritance & Locus & Gene \\
ALS 1 & AD / AR & $21 q 22.21$ & SOD1 \\
ALS3 & AD & $18 q 21$ & \\
ALS6 & AD & $16 q 12$ & \\
ALS7 & AD & $20 p t e l$ & \\
Juvenile ALS (ALS2) & AR & $2 q 33$ & \\
Juvenile ALS (ALS4) & AD & $9 q 34$ & \\
Juvenile ALS (ALS5) & AR & $15 q 15-22$ & Tau \\
ALS with FTD & AD & $9 q 21-22$ & Androgen receptor \\
ALS with D/P & AD & $17 q 21.11$ & \\
Kennedy disease & XR & Xq11-Xq12 & \\
\hline
\end{tabular}

ALS: amyotrophic lateral sclerosis; FTD: fronto temporal dementia; D/P: dementia and Parkinsonism; AD: autosomal dominant; AR: autosomal recessive; XR: X-linked recessive; SOD1: superoxide dismutase.

\section{PATHOGENESIS}

No period of medicine has been without controversy and the nineteenth century was no exception. After motor neuron disease was recognized, Duchenne believed for several years that the aetiology of the process was in the muscles. Cruveiller stated that it was of neural origin. The followers of Leyden (German Scholl) and Charcot (French Scholl) argued over the role of white matter versus motor neuron. Charcot placed emphasis on lesions of nerve cells, while Leyden contended that all cases of both PBP and SMA had lesions of the white matter.

Since its description by Charcot, more than 130 years ago, the pathogenesis of selective motor neuron degeneration in amyotrophic lateral sclerosis remains unsolved. Over the last 20 years, and the past ten years in particular, our understanding of cellular changes in nerve cells has expanded enormously. This increase in knowledge occurred because of advances in neurochemistry and as sophisticated experimental techniques became available. Two important steps were the discovery of mutations of the super oxide dismutase gene for same cases of familial ALS and the ability to make transgenic mouse model of MND.

Over the years, many pathogenic mechanisms have been proposed and the multitude of contributing factors indicates that ALS is a complex disease and also suggests that it is a multifactorial disorder. Amongst others these include: oxidative stress, excitotoxicity mediated by glutamate, toxic effects caused by the mutation of super oxide dismutase1, inclusion of the abnormal protein aggregation, intermediaries filaments disorganization, changing the anterograde and retrograde axonal transport, microglial activation, inflammation, and growth factor deficiency $y^{25,26}$. Genetic factors, changes in intracellular calcium levels in motor neurons, and programmed cell death (apoptosis) have also been linked to the development of $\mathrm{ALS}^{27,28}$.
As all roads lead to the proverbial Rome, we discuss here how distinct molecular pathways may converge to the same final result that is motor neuron death. Recent research has provided many hypotheses to explain the selective degeneration of motor neurons ${ }^{29}$. Lower motor neurons in the brain stem or spinal cord innervate multiple muscle fibers through length axons. These motor units may differ in size but all share a similar organization. Once damaged, motor neurons can not regenerate. As a consequence, denervated muscle fibers can only be reinnervated by nearby axon branches of surviving motor neurons. With ongoing disease the balance between denervation and reinnervation will shift towards denervation. The time course of this process determines progression of disease (Fig 1).

\section{Excitotoxicity}

Is not the newest and most spectacular hypothesis in the ALS field, but it is undoubtedly one of the most robust pathogenic mechanisms supported by an impressive amount of evidence. Excitotoxicity is the pathological process by which nerve cells are damaged and killed by glutamate and similar substances.

After its release from synaptic terminals, glutamate activates three different receptor subtypes in postsynaptic neurons: N-methyl-d-aspartate (NMDA) receptors; non-NMDA receptors, sensitive to $\alpha$-amino3-hydroxy5-methyl-4-isoxazolepropionic acid (AMPA) and kainic acid; and metabotropic receptors. Activation of nonNMDA receptors induces the influx of sodium ions and the subsequent depolarization of the plasma membrane, promoting the extrusion of the magnesium ion normally blocking the NMDA receptor channel. Once the magnesium ion is extruded, binding of glutamate and its coagonist, glycine, to their respective sites fully activates NMDA-receptors, allowing the influx of sodium and $\mathrm{Ca}^{2+}$ 

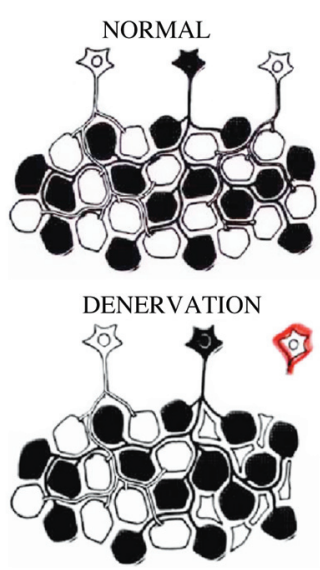

PROGRESSIVE LESION

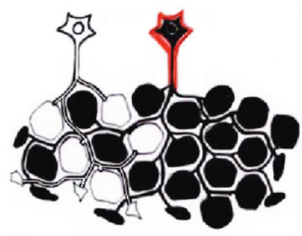

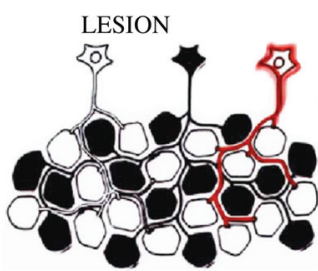

REINERVATION

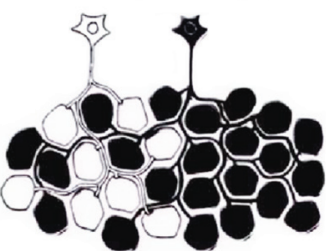

PROGRESSIVE DENERVATION

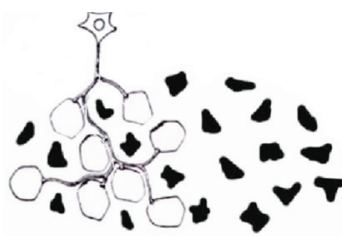

Fig 1. Schematic representation of various stages in chronic process of denervation and reinervation. (1.1) Three motor units, two type 1 units (white) and one type 2 (black). The muscle fibers assume a mosaic pattern (type 1 muscle fibers surrounded by type 2 muscle fibers). (1.2) Partial loss of motor neuron leads to muscle fiber atrophy secondary to denervation. (1.3) Successful reinervation by collateral sprouts from a nearby intramuscular axon. The mosaic pattern is replaced in part by a group of histochemistry uniform type fibers (type grouping). (1.4) The enlarged motor unit is denervated, resulting in a group of histochemistry uniform atrophic muscle fibers (neurogenic amyotrophy) ${ }^{30}$.

ions into the cell. Metabotropic receptors are coupled to G-proteins and induce the activation of second messenger systems such as inositol-3-phosphate (IP-3), triggering the release of $\mathrm{Ca}^{2+}$ from the endoplasmic reticulum. The extra cellular concentration of glutamate is highly regulated through specific $\mathrm{Na}^{+}$-dependent high affinity transporters (neuronal excitatory amino acid carrier - EAACl; glutamate-aspartate transporter - GLAST; glutamate transporter 1 - GLT-1; excitatory amino acid transporter - EAAT) located both in neurons and glial cells. Glutamate taken up by glial cells is metabolized to glutamine, which in turn is released to the extra cellular space and taken up by neurons, where it is again converted to glutamate to replenish the neurotransmitter pool homeostasis of glutamatergic neurotransmission depends on the coordinated activity of its different components, and failure in any one of them can lead to excitotoxic neuronal damage. Impairment of glutamate removal after its synaptic release leads to the accumulation of the amino acid in the synaptic cleft. The subse- quent sustained activation of glutamate receptors may trigger excitotoxic neuronal death, in particular during ATP limiting conditions (Fig 2).

\section{Protein misfolding}

Diseases result from the toxicity associated with the conversion of the native state of a protein into a pathologically misfolded conformation induced by mutation and/or environmental triggers. In $20 \%$ of familial amyotrophic lateral sclerosis mutations in super oxide dismutase cause the protein to misfold and form intracellular inclusions. Toxicity of these cytoplasmic aggregates is thought to arise from aberrant interactions with the protein-folding chaperone system or from inhibition of proteasomes. Toxicity has also been proposed to result from aberrant interactions with mitochondrial proteins such as Tom 20 or $\mathrm{Bcl}-2$ because SOD1 has been detected in mitochondria from the spinal cord and brain, and mitochondrial vacuolization is an early event in ALS models.

\section{Neurofilaments (NFs)}

Are the most abundant cytoskeletal component of motor axons. They are made of NF subunit proteins whose expression levels must be tightly coordinated to maintain neuronal homeostasis; imbalances in this expression can lead to aggregation of NFs, a hallmark of ALS. NF expression is controlled not only transcriptionally, but also post-transcriptionally. Recent studies have implicated aberrant post-transcriptional regulation as a likely contributing factor to the neurodegenerative disease process.

\section{Protein aggregation}

Is a pathological hallmark of many neurodegenerative diseases, including ALS. Whether aggregation is a cause or a consequence of disease is fiercely debated, and this debate is fuelled by evidence both for and against the toxicity of protein aggregates ${ }^{32}$. Protein aggregation can result from intrinsic factors such as changes in protein thermodynamic stability, charge, the propensity to form $\alpha$-helices and $\beta$-sheets, and hydrophobicity. Recent studies have developed algorithms that predict how a given mutation affects protein aggregation rates ${ }^{33}$ and have demonstrated that in vitro protein aggregation rates depend upon physicochemical properties, specifically changes in charge, hydrophobicity, and secondary structure.

\section{Basic Fibroblast Growth Factor (bFGF) and} Insulin-like Growth Factor-1 (IGF-1)

Are trophic factors for motor neurons and glia. In neurodegenerative disease, unbalance between neurotrophic and neurotoxic factors ultimately causes mo- 


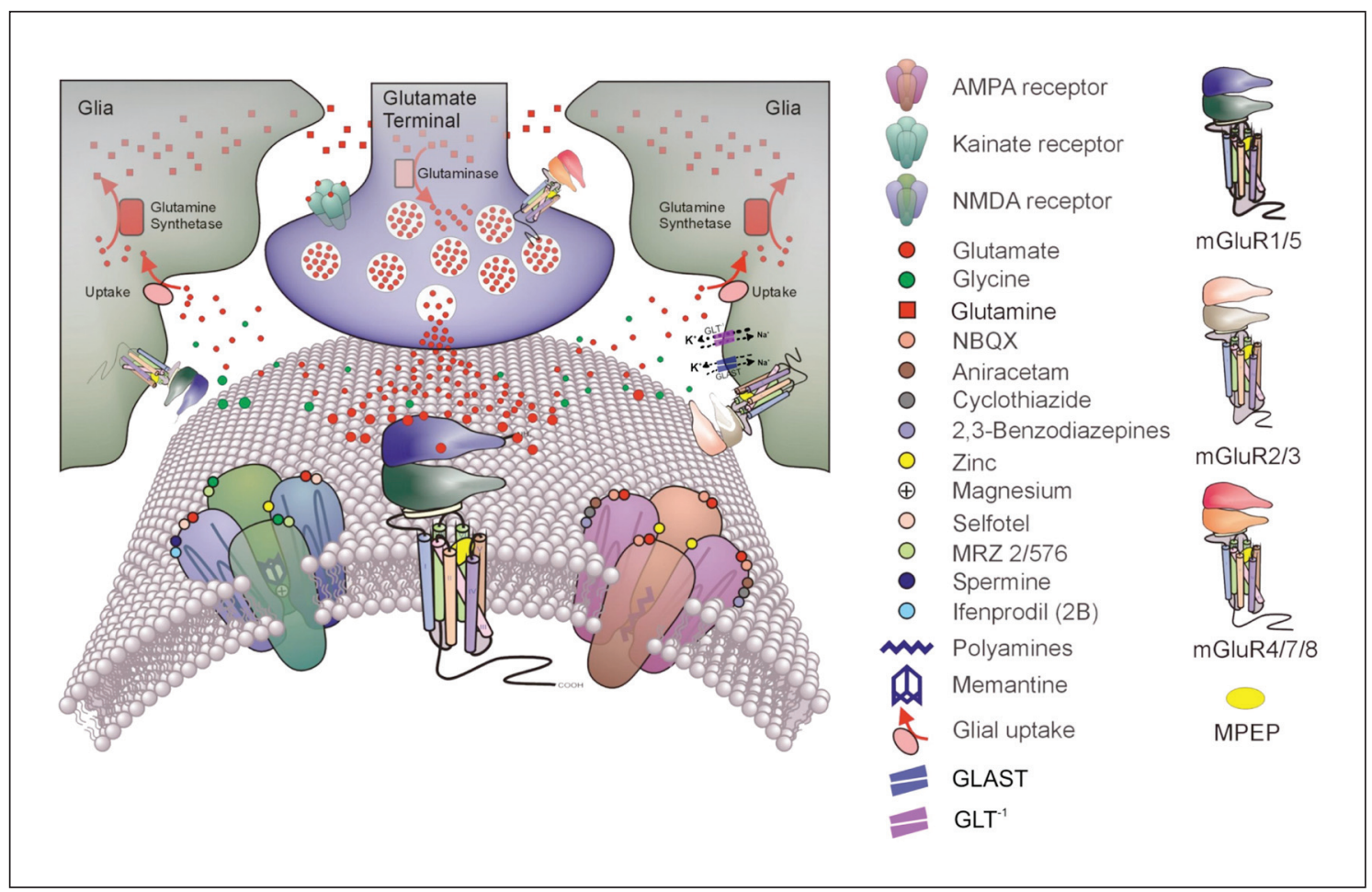

Fig 2. Glutamatergic neurotransmission and the excitotoxic cell death cascade. Depolarization of the presynaptic terminal after the arrival of the synaptic potential induces the influx of calcium and the fusion of vesicles, releasing glutamate to the synaptic cleft. Glutamate activates AMPA receptors on the post-synaptic neuron inducing the influx of sodium and the depolarization of the plasma membrane. The release of magnesium normally blocking the NMDA receptor, leads to its activation and to the influx of calcium into the cell. Glutamate is eliminated from the extracellular medium by specific proteins located both in astrocytes (GLT-1 and GLAST) and in neurons (EAAC1). Glutamate is metabolized to glutamine in glial cells by glutamine synthetase (GS), which is then release and taken up by neurons. Altered glutamate uptake induces glutamate accumulation, which might result in cell death. Massive calcium influx during NMDA receptors over activation stimulates the activity of diverse enzymes targeting essential components of the cell. Calcium also induces the production of reactive oxygen species, mitochondrial failure and oxidative damage to lipids, proteins and DNA. Mitochondrial dysfunction might disrupt ATP production contributing to cell death $)^{31}$.

tor neuron cell death (by a direct effect and/or by activating gliocytes which in turn might initiate apoptotic pathways in motor neurons themselves). Functional abnormalities in the regulation of angiogenic abnormalities in the regulation of angiogenic factors (PGE-2 / VEGF and Angiopoietin-2 / VEGF - vascular endothelial growth factor) during hypoxia could be implicated in motor neuron degeneration. This could be relevant during ALS progression since acute intermittent hypoxia frequently occurs particularly due to diaphragmatic failure.

\section{Mitochondrial damage}

In the course of motor neuron degeneration in amyotrophic lateral sclerosis and mutant SOD1 transgenic animal models of familial ALS has been demonstrated in recent studies.

\section{Apoptosis}

Is the cell death caused by structural or intracellular metabolic disorders, and the mark of many neurodegen- erative diseases such as ALS, Alzheimer and Parkinson diseases. It is very important to note the variety phenotypic involving the motor neuron disease, with typical findings. Clinical presentations of ALS and their prognoses, as the form distal in limbs and bulbar, are well known, however, knowledge of specific forms such as brachial paraplegia or "flail arm syndrome", monomelic atrophy of Hirayama, progressive muscular atrophy, hereditary motor neuronopathy (HMN), provides the link between databases and molecular pathogenesis, increasingly known through research, which has contributed to the knowledge of specific mechanisms of cellular apoptosis involving the ALS (Figs 3 and 4).

DNA damage triggers apoptosis by accumulation and transcriptional activation of the tumour-supressor protein $p 53$ that occurs rapidly in response to a wide variety of insults including DNA damage, oxidative stress, metabolic compromise or excitotoxicity. Depending on the initial stress stimulus activation of $p 53$ occurs via various pathways that may interact each other upstream of $p 53$ 


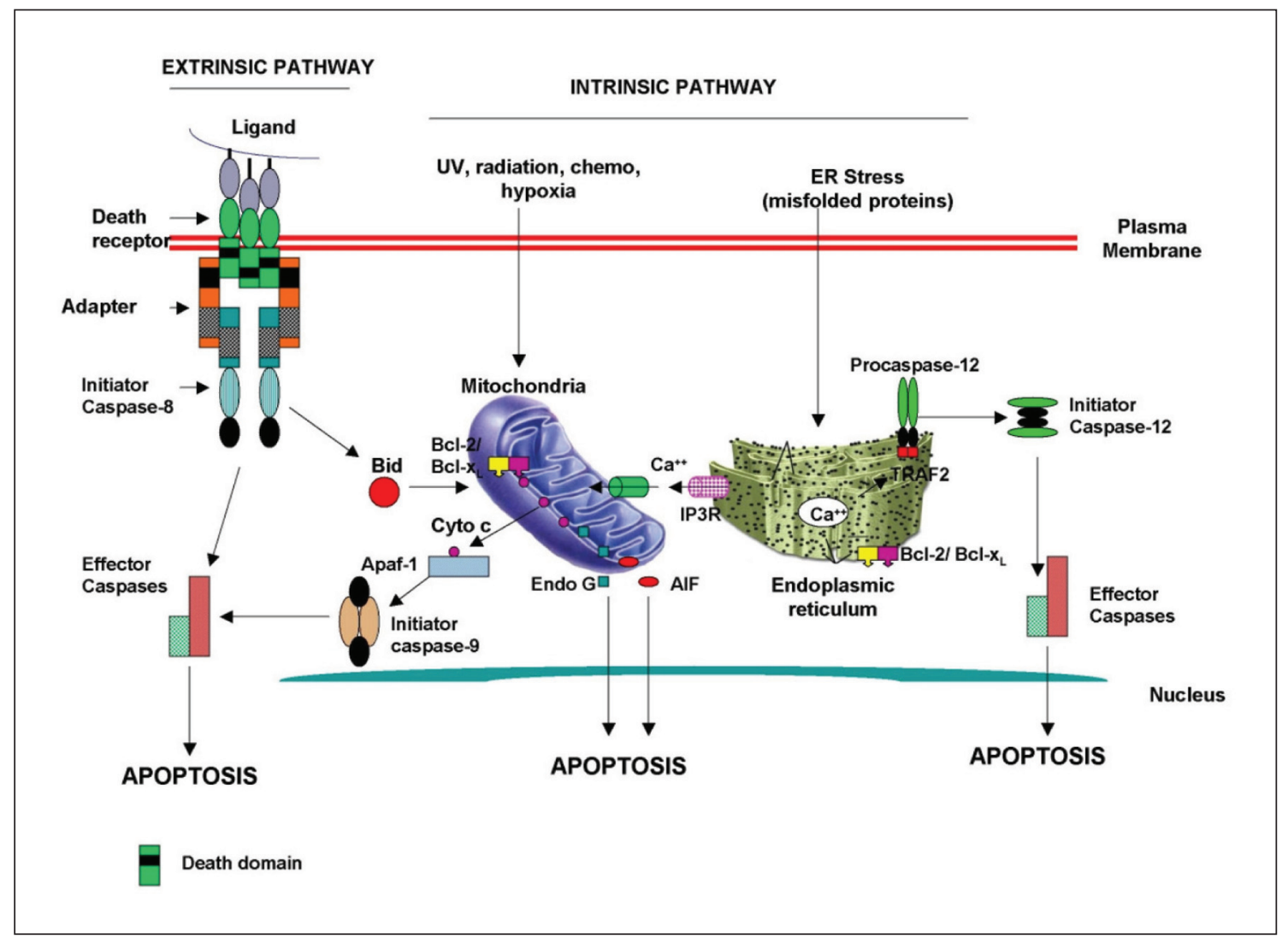

Fig 3. Death receptor and intrinsic pathways of apoptosis. Intrinsic pathway is mediated by mitochondrial and the endoplasmic reticulum pathways. Distinct initiator caspases are activated in each pathway of apoptosis ${ }^{34}$.

activation. p53 exerts its deadly function by transactivation of pro-apoptotic target genes PUMA ( $p 53$-upregulated modulator of apoptosis) and NOXA, which translocate to mitochondria where they mediate disruption of the mitochondria membrane potential and release of apoptotic factors including cytocrome $C$. Many other transcriptional targets such as Peg3/Pwl, Siah-1 and SIVA act in a similar way by interacting with pro-apoptotic members of the BCL-2 family at the level of mitochondria. In addition, p53 may promote cell death via transactivation of the death receptor Fas or upregulation of APAF-1 (apoptotic-protease-activating factor 1 ) which promotes caspase-dependent apoptosis after formation of the apoptosome with cytocrome $C$ and caspase-9. p53 can directly trigger apoptosis after translocation to mitochondria, a process that can occur in synapses (synaptic apoptosis) and may involve interactions with BAX or BCL-xl (BCL-2associated $X$ protein). DNA-damage-induced apoptosis is also inhibited by loss of BIM (B-cell lymphoma 2 (BCL-2) -interacting mediator of cell death), but how DNA damage activates BIM is not clear. Glucocorticoids kill lymphocytes by a mechanism that requires PUMA and BIM. How PUMA and BIM are activated by glucocorticoids is not yet clear, but it is probable that the glucocorticoid receptor is involved. Cytokine withdrawal kills haematopoi- etic and neuronal cells by a BIM-dependent and/or PUMA-dependent mechanism. HRK (harakiri) has a role in growth-factor-withdrawal-induced cell death of certain neuronal populations, and BAD (BCL-2-antagonist of cell death) seems to have a minor role in this process in haematopoietic cells, mammary epithelial cells and fibroblasts. Antigen-receptor crosslinking triggers apoptosis of $B$ and $T$ cells in a BIM-dependent manner. BIK (BCL2-interacting killer) was shown to be activated by $\mathrm{B}$-cell receptor (BCR) crosslinking in human $B$ cells, but no defect in BCR-stimulation-induced apoptosis was observed in Bik-/- mice. BID (BCL-2-homology domain 3 (BH3)-interacting-domain death agonist) is activated by caspase-8mediated proteolysis in response to death-receptor stimulation, and this is crucial for this apoptotic pathway in hepatocytes but not in lymphoid cells. BMF (BCL-2-modifying factor) is activated by loss of cell attachment (also known as anoikis), but it is not yet clear whether BMF is essential for the execution of this apoptotic stimulus.

A neuroprotective role for the DNA repair enzyme DNA-dependent protein kinase (DNA-PK) in neurons has been described. Neurons lacking DNA-PK were highly susceptible to various insults in vitro and in vivo, exposing DNA repair as an essential mechanism of endogenous survival signaling. Using the $\mathrm{p} 53$ inhibitor pifithrin-alpha (PFT) 


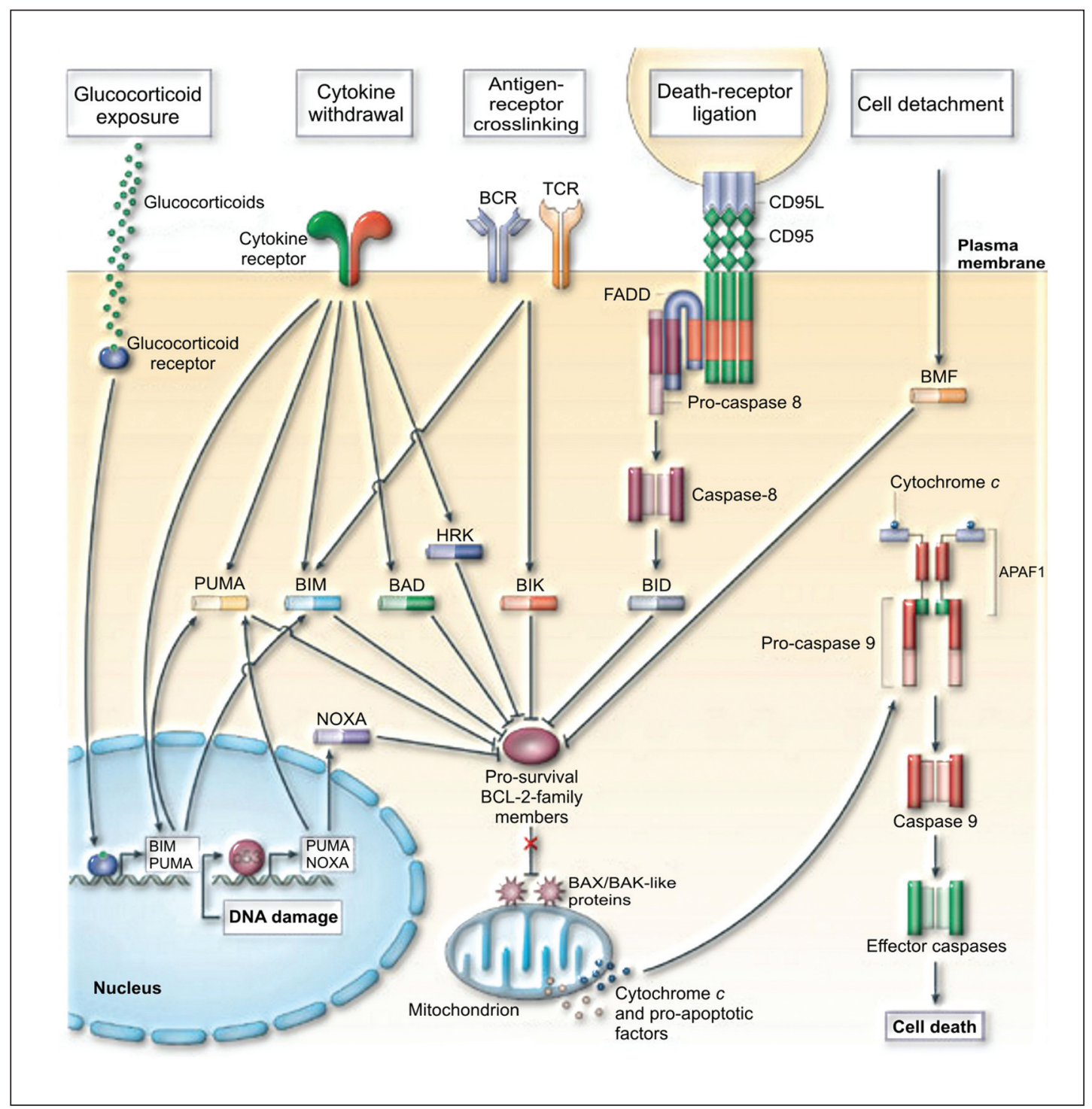

Fig 4. DNA damage triggers apoptosis by accumulation and transcriptional activation of the tumour-supressor protein $p 53$ that occurs rapidly in response to a wide variety of insults including DNA damage, oxidative stress, metabolic compromise or excitotoxicity ${ }^{35}$.

and other newly synthesized analogues it was been possible to demonstrate the essential role of $p 53$ in various in vitro and in vivo models relevant to neurodegenerative disorders. The latest results exposed reversible inhibition of $\mathrm{p} 53$ as a promising therapeutic strategy in neurological disorders, because p53 inhibitors block the apoptotic cascade and concomitantly enhance endogenous protective signaling through NF-kB, even if administered up to $6 \mathrm{~h}$ after ischemia or brain trauma ${ }^{36}$.

\section{Involvement of the immune system}

Complement deposition, anti-neuronal antibodies and increased incidence of lympho-proliferative disorders in sporadic ALS patients support the hypothesis of involvement of the immune system, possibly as a second- ary event ${ }^{37}$. Transgenic mouse studies indicate that microglial activation precedes astrocytosis and neuronal loss in the spinal cord.

\section{Microglia activation}

One of the most studied hypotheses is the putative role of the inflammatory response that accompanies motor neuron death. The proliferation of microglia and astrocytes has been considered to be a secondary phenomenon, but recently, evidence is accumulating in favor of a contributory role of the non-neuronal cell populations to the pathogenesis of the disease. In this review, we will introduce the characteristics of microglial cells in the central nervous system. We will summarize the evidence of the expansion and the activation of the microglial cell 
population that accompanies motor neuron degeneration. Finally, an overview will be given of the different therapeutic strategies that targeted the inflammatory process in amyotrophic lateral sclerosis ${ }^{38}$.

\section{Environmental toxicants}

Such as heavy metals, pesticides, and chemicals appear to be risk factors for sporadic amyotrophic lateral sclerosis. Even in the familial cases there must be an environmental factor that precipitates the onset. An impaired ability to break down these toxicants because of differences in detoxification genes could underlie some cases of this disease ${ }^{39}$.

Cyanobacteria is associated with many neurotoxins and cytotoxins including BMAA ( $\beta-\mathrm{N}$-methylaminoL-alanine), anatoxin, saxitoxin, curacin, microcystins and cylindrospermopsin. All of the neurotoxins have targets on the central or peripheral nervous system. The ubiquity of cyanobacteria in terrestrial, as well as freshwater, brackish, and marine environments suggests a potential for wide-spread human exposure. BMAA, produced by symbiotic cyanobacteria present in the cycad roots, was first proposed as a contributor to the dementia complex (ALS/PDC) that has been remarkably prevalent amongst the Chamorro people of Guam.

BMAA is a non-natural neurotoxic amino acid that becomes incorporated into the proteins of higher organisms. Protein-bound BMAA has become found in brains of Chamorros, living in the South Pacific island of Guam. More recently, BMAA has been measured in cohorts of Caucasian, North American patients dying from sporadic Alzheimer's disease and ALS. Although the role of BMAA in human degenerative disease is highly debated, there is evidence to suggest BMAA may mimic glutamate toxicity and could explain the sporadic unexplained ALS cases. However, concerns about the apparent low potency of this toxin in relation to estimated levels of human ingestion led to doubts about its disease relevance.

BMAA is transported across the blood-brain-barrier via the high affinity saturatable L1 system that carries large neutral essential amino acids (leucine, valine, methionine, histidine, iso-leucine, tryptophan, phenylalanine, threonine). BMAA has no direct excitatory effects unless the exposure was carried out in the presence of bicarbonate. When associated to bicarbonate, BMAA assumes a structure resembling glutamate and capable of activating glutamate receptors, inducing selective motor neurons loss, even in lower BMAA concentrations ${ }^{40}$.

\section{RISK FACTORS}

\section{Muscle exercise}

ALS has been frequently associated with heavy work and sport practice in the literature, but data largely re- main in dispute. Studies of sub-groups such as professional soccer players, marathonians or military veterans suggest highly significant Odd Ratios as high as 20 in favor of an increased risk to develop ALS ${ }^{41}$.

\section{Soccer link to motor neuron disease}

Piazza et al. described an increased incidence of ALS in Italian professional soccer players. They diagnosed 33 ALS cases in a subpopulation of 24,000 soccer players of the top three Italian divisions from the 1960s to 1996 and considered the repetitive brain trauma that soccer players experience for controlling and advancing the ball with their heads as an environmental risk factor for developing ALS in genetically predisposed individuals ${ }^{42}$.

Other studies have confirmed claims that Italian professional soccer players have a higher than normal risk of developing motor neuron disease. Taioli'study indicates that overall mortality and mortality rates from cancer and cardiovascular diseases in this population are significantly lower than expected in the general population of the same age. However, mortality rates for ALS and car accidents are significantly higher than expected, and for ALS the risk is 18 times than expected ${ }^{43}$.

Adriano Chiò's team at the University of Turin surveyed the medical records of 7325 professional footballers who played in Italy's first or second division between 1970 and 2001. Based on the normal incidence of the disease and the players' ages, the researchers calculated that there should have been 0.8 cases of ALS in this group. Instead, there were five. The study was prompted by what the Italian press dubbed "the motor neuron mystery" the discovery a few years ago of 33 cases of ALS during an investigation of illicit drug use among 24,000 pro and semi-pro players in Italy. Dubious about the methodology of that initial investigation, Chiò's group applied stricter diagnostic criteria to their data, such as only including players born in Italy. The researchers found that the mean age of onset was just 41, 20 years earlier than usual, and the longer people play football the greater the risk. Clusters of cases have been reported in American football, but until now no large-scale studies have found any clear link between sport and ALS. The cause of ALS remains unknown, as does the reason for the higher rate among footballers. Genes undoubtedly contribute, but the disease could be triggered by head trauma, performance-enhancing drugs or some other toxin to which footballers are exposed. Certain viruses are also being investigated as potential causes ${ }^{44}$.

\section{LIFETIME OCCUPATION, EDUCATION AND SMOKING}

The univariate analysis done in 364 patients and 392 controls showed an increased risk of developing ALS among current cigarette smokers (OR=1.7; $95 \% \mathrm{Cl}=1.1$ to 
2.6; $p=0.01$ ), those with a low level of education (elementary school) ( $\mathrm{OR}=2.2 ; 95 \% \mathrm{Cl}=1.2$ to $3.8 ; \mathrm{p}<0.01$ ), and among women whose main occupation was classified as crafts and related trades workers (OR $=8.4 ; 95 \% \mathrm{Cl}=1.0$ to 70.1 ; $\mathrm{p}=0.05$ ). Multivariate analysis (with covariates age, smoking, education, and occupation) showed an increased risk for current smokers of cigarettes (OR=1.6; $95 \% \mathrm{Cl}=1.0$ to $2.5 ; p=0.04)$. It was concluded that occupation, education, and cigarette smoking are risk factors for amyotrophic lateral sclerosis, but only smoking appeared independently associated ${ }^{45}$.

\section{GULF WAR VETERANS}

A nationwide epidemiologic case ascertainment study design was used to ascertain all occurrences of ALS for the 10-year period since August 1990 among active duty military and mobilized Reserves, including National Guard, who served during the Gulf War (August 2, 1990, through July 31, 1991). Among approximately 2.5 million eligible military personnel, 107 confirmed cases of ALS were identified for an overall occurrence of 0.43 per 100,000 persons per year. A significant elevated risk of ALS occurred among all deployed personnel ( $R R=1.92 ; 95 \% C L=1.29,2.84$ ), deployed active duty military ( $R R=2.15,95 \% C L=1.38,3.36)$, deployed Air Force (RR=2.68, 95\% CL=1.24, 5.78), and deployed Army ( $R R=2.04 ; 95 \% \mathrm{CL}=1.10,3.77$ ) personnel. Elevated, but no significant, risks were observed for deployed Reserves and National Guard ( $R R=2.50 ; 95 \% C L=0.88$, 7.07), deployed Navy (RR=1.48, 95\% CL=0.62, 3.57), and deployed Marine Corps (RR=1.13; 95\% CL=0.27, 4.79) personnel. Overall, the attributable risk associated with deployment was $18 \%$ (95\% CL=4.9\%, 29.4\%). Military personnel who were deployed to the Gulf Region during the Gulf War period experienced a greater post-war risk of ALS than those who were not deployed to the Gulf ${ }^{46}$.

\section{PROGNOSTIC FACTORS}

A systematic review to summarize current knowledge concerning factors related to survival in ALS and to evaluate the implications of these data for clinical trials design was done by Chiò e colleagues. The median survival time from onset to death ranges from 20 to 48 months, but $10-20 \%$ of ALS patients have a survival longer than 10 years. Older age and bulbar onset are consistently reported to have a worse outcome. There are conflicting data on gender, diagnostic delay and El Escorial criteria. The rate of symptom progression was revealed to be an independent prognostic factor. Psychosocial factors, FTD, nutritional status, and respiratory function are also related to ALS outcome. The effect of enteric nutrition on survival is still unclear, while NIPPV has been found to improve survival. There are no well established biological markers of progression, although some are likely to emerge in the near future. These findings have relevant implications for the design of future trials. Randomization, besides the type of onset, should take into account age, respiratory status at entry, and a measure of disease progression preentry. Alternative trial designs can include the use of natural history controls, the so-called minimization method for treatment allocation, and the futility approach ${ }^{47}$.

In other study to identify prognostic factors for survival in ALS, performed in France, a cohort of 2069 patients fulfilling broad entry criteria treated with riluzole, included a over 100 demographic, biological, clinical and quality-of-life variables were monitored and assessed for their effect on survival. Thirteen variables were found to affect survival independently and were used to construct a survival prediction score, RL401. These included age, disease duration, slow vital capacity, intensity of tiredness (visual analogue scale), number of body levels with spasticity, atrophy and/or fasciculations, cough, distal muscle strength, household income, depression and two biological parameters, plasma creatinine levels and neutrophil counts. A simplified score, RL401s, was constructed, designed to be easy to use and interpret. The predictive powers of the two scores were similar ${ }^{48}$.

\section{ELECTROPHYSIOLOGY, IMAGING AND \\ MARKERS OF DISEASE PROGRESSION}

There are no current diagnostic tests for ALS or surrogate markers of disease progression. Surrogate markers of ALS disease progression would be valuable measurements for drug efficacy in clinical trials and also to identify new targets for drug therapy.

\section{CLINICAL ELECTROPHYSIOLOGY}

A consensus meeting (Consensus of an International Symposium sponsored by IFCN), December 3-5, 2006, in Awaji-shima, Japan) was held to determine the best use and interpretation of electrophysiological data in the diagnosis of ALS. The utility of needle EMG and nerve conduction studies was affirmed. It is recommended that electrophysiological evidence for chronic neurogenic change should be taken as equivalent to clinical information in the recognition of involvement of individual muscles in a limb. In addition, in the context of a suspected clinical diagnosis of ALS, fasciculation potentials should be taken as equivalent to fibrillation potential and positive sharp waves in recognising denervation. The importance of searching for instability in fasciculations potentials and in motor unit potentials in ALS is stressed. These changes in the interpretation of electrophysiological data render obsolete the category probable laboratory-supported ALS in the modified El Escorial diagnostic criteria for $\mathrm{ALS}^{49}$.

Gutierrez et al. ${ }^{50}$ demonstrate that, in early stage of 
ALS, distal muscles are more affected tan axial and proximal muscles. Fasciculation, fibrillation, PSW, reinervation potentials and decreased recruitment patterns were significantly more frequent and severe in distal limb muscles, especially in upper limbs, than in their corresponding axial and proximal muscles. The most affected items of the ALSFRS were those related to fine hand movements (handwriting, cutting food) and language. There was significant correlation between electrophysiological and functional involvement of hand muscles. Items related to gross movements (climbing stairs, walking, turning in bed) and dependent on proximal and axial muscles, were relatively preserved at this stage of the disease. Median nerve distal latencies (both motor and sensory) and motor conduction velocity (elbow-wrist) were affected in $52 \%$ of the patients, despite normal amplitude of the responses.

Clinical neurophysiological techniques, including Neurophysiological Index, motor unit counting methods (MUNE), and transcranial magnetic motor cortex stimulation appear to be useful in measuring change in clinical trials in ALS. MUNE, M-wave amplitude and the Neurophysiological Index are sufficiently reliable, sensitive, and relevant to the clinical problem of ALS, to be used in clinical trials in the disease. Transcranial magnetic stimulation is of limited value, but a combination of the measurements made as part of this technique may also be useful ${ }^{51}$.

\section{IMAGING}

Methods for detection of upper motor neuron abnormality appear sensitive but require further study, particularly regarding their value when clinical signs of upper motor neuron lesion are uncertain.

Proton magnetic resonance spectroscopic imaging (MRSI) can non-invasively detect neuronal loss or dysfunction by demonstrating a low signal from the neuronal marker $\mathrm{N}$-acetylaspartate (NAA) relative to creatine $(\mathrm{Cr})$ or choline (Cho). Previous studies have demonstrated decreased NAA/Cr in the motor cortex of ALS patients.

Diffusion tensor (DT) MRI imaging is a quantitative MRI technique. DT MRI allows the measurement of quantities reflecting the size, such as the apparent diffusion coefficient (ADC) and orientation such as fractional anisotropy (FA) of water- filled spaces in biological tissues. Compared to controls, ALS patients had significantly lower FA (pv0.01) in posterior limb of internal capsule, cerebral peduncle, corticospinal tract (CST) and corticobulbar tract. $A D C$ values of $A L S$ patients were significantly higher than those of controls in posterior limb of internal capsule, cerebral peduncle, CST and corticobulbar tract. Finally, a significant correlation was found between FA values and the ALSFRS-R. ADC values were inversely correlated with the disease severity ${ }^{52}$.

\section{BIOMARKERS}

Research is also needed in order to identify protein biomarkers that correlate to clinical measurements of ALS and disease progression. Disease biomarkers provide a more effective therapy, since pharmacotherapy is most beneficial when given early in the course of MND.

\section{CEREBROSPINAL FLUID}

Cerebrospinal fluid (CSF) is a promising source of biomarkers in amyotrophic lateral sclerosis (ALS):

\section{Levels of neurofilament light (NF-L) protein}

A marker of axonal degeneration, might provide diagnostic and prognostic information on the disease. A study including 60 sporadic and 19 familial ALS patients, 206 reference patients with other neurological disorders and 40 age- and sex-matched healthy controls showed that CSF levels of NF-L. concentration [median (range)] was strongly elevated in ALS [2110 (255-10 800) ng/L] compared with reference patients and healthy controls $[277(<125-15506)$ and $175(<125-710) \mathrm{ng} / \mathrm{L}$, respectively, $\mathrm{p}<0.001]$ and correlated inversely with disease duration (Spearman $R=-0.518$, $\mathrm{p}=0.001)^{53}$.

\section{Cystatin C protein, phosphor-neurofilament}

\section{$\mathrm{H}$ and anti-thrombin III protein}

A prospectively collected CSF and blood plasma every 4 months was performed in 24 ALS patients and 14 control subjects over a 2-year time frame. The data indicates that cystatin $\mathrm{C}$ protein may have utility as a surrogate biomarker and could differentiate fast versus slow progression (levels in both the CSF and plasma decrease over time in ALS patients that exhibit rapid clinical disease progression. In addition, phosphor-neurofilament $\mathrm{H}$ and anti-thrombin III protein levels were also altered (increased levels) during ALS disease progression ${ }^{54}$.

\section{Proteome analysis}

Using the two-dimensional difference in gel electrophoresis (2-D-DIGE), CSF samples from patients with ALS $(n=14)$ were compared with those from normal controls $(n=14)$. Protein spots that showed significant differences between patients and controls were selected for further analysis by MALDI-TOF mass spectrometry. The identified proteins, two were upregulated and three were down-regulated in CSF in ALS. Of these, two proteins (Zn-alpha-2glycoprotein and ceruloplasmin precursor protein) have not been reported in CSF of patients with ALS so far. In contrast, several other proteins (transferrin, alpha-1-antitrypsin precursor and beta-2-microglobulin) seem to be unspecifically affected in different neurological diseases and may therefore be of limited value as disease-related biochemical markers in $\mathrm{ALS}^{55}$. 


\section{DIFFERENTIAL DIAGNOSIS}

It is now recognized that incorrect diagnosis of ALS is a significant problem, and several studies over the past two decades have collected data indicating that rates of misdiagnosis in the general medical population are high $\mathrm{h}^{56-59}$. The diseases that more commonly cause a diagnostic dilemma are wide (Table 11).

The adult-onset spinal muscular atrophies, which encompass a very broad range of primary motor neuron disease, have been classified either by pattern of inheritance, distribution of weakness, or age of onset (Table 12).

\section{IMPORTANT CLINICAL CHARACTERISTICS}

\section{Cognitive and psychological change}

ALS was traditionally thought to affect solely the lower motor neurons and corticospinal tracts, with the mind and senses remaining intact. Indeed, much of the patient literature and information in medical textbooks continues to promote this myth. Recent studies suggest that the pathogenic processes of ALS are more extensive, involving dysfunction of cortical grey and white matter with clinical correlates of impairment in cognition and language. In reality, at least a subgroup of ALS patients experience personality changes and cognitive problems consistent with fronto-temporal dementia (ALS-FTD). Neuropsychological, neuropathology, and more recently genetic studies have started to unravel an underlying shared mechanism beneath ALS and FTD. Until recently cognitive deterioration was associated almost exclusively with a subgroup of 3-5\% ALS patients with frontotemporal dementia. However, a number of neuropsychological investigations including the Cambridge Behavioral Inventory (CBI) have been used to help detect the behavioral and neuropsychiatry manifestations of FTDys ${ }^{60}$

Table 12. Adult-onset spinal muscular atrophies.

Proximal predominance

- Spinal muscular atrophy

Segmental spinal muscular atrophy

- Flail arm syndrome

- Flail leg syndrome

- Monomelic atrophy (Hirayama syndrome)

Spinal-bulbar

- Kennedy's disease

Scapuloperoneal

Distal predominance

Asymmetric or unclassifiable

Other diseases that must be included in the list of differential diagnosis of ALS:

- Machado-Joseph disease

- Celiac disease
Table 11. Diseases that more commonly cause a diagnostic dilemma with ALS /MND.

With UMN signs

- Hereditary spastic paraparesis

- HTLV-1-associated myelopathy

- Multiple sclerosis

- Stroke syndrome with spastic hemiparesis

- Toxic spastic paraparesis: caused by ingested foodstuff toxins

- Lathyrism (derived from the chickling pea vetch containing- $\beta$ oxalil-L-aminoacid)

- Konzo (due to toxic cyanogenic cassava)

With LMN signs

- Other motor neuronopathies

- Adult-onset Spinal muscular atrophies

- Post-Polio syndrome

- Compressive radiculopathy: cervical; lumbosacral

- Entities with fasciculation

- Benign fasciculations

- Diseases of motor root, plexus and peripheral nerve

- Mononeuropathy

- Entrapment

- Mononeuropathy multiplex

- Multifocal motor neuropathy with or without conduction block

- Plexopathy

- Brachial plexus neuropathy

- Diabetic amyotrophy

- Neurogenic thoracic outlet syndrome

- Polyneuropathy

- Endocrine polineuropathy: Diabetes

- Hereditary motor and sensory neuropathy (Charcot-MarieTooth)

- Infectious polyneuropathy: Lyme, HIV

- Motor variant of chronic inflammatory demyelinating neuropathy

- Toxic polineuropathy: heavy metals

- Neuromuscular junction defect

- Myasthenia gravis

- Myasthenic syndrome

- Myopathy

- Distal myopathy

- Inclusion body myositis

- Polymiositis

With combination of UMN and LMN

- Cervical spondylosis with myelopathy and radiculopathy

- Syringomyelia

- HIV infection (Aids)

- Spirochetal infections: syphilis; Lyme disease

- Adrenomyeloneuropathy

- Adult polyglucosan body disease

- Organophosphate toxic neuropathy

- Central neurofibromatosis

With bulbar symptoms

- Structural brain lesion: tumour; stroke

- Pseudo bulbar palsy

- Syringobulbia

- Myasthenia gravis 
recently demonstrated selective impairments in executive and memory function in no demented ALS patients in higher proportion (25-75\%).

Although the cause(s) of this process remain to be defined, as with the clinical heterogeneity, there is likely to be significant biochemical heterogeneity. This includes alterations in tau protein metabolism which are present in a proportion of familial and sporadic ALS cases, as well as the western Pacific variant, and recently described alterations in the metabolism of the TAR DNA binding protein $43(\text { TDP-43) })^{61}$.

\section{ANIMAL MODELS}

The neuropathological results obtained from human ALS autopsy cases are valuable and important to understand ALS. However, almost all of such cases represent only the terminal stage. This makes it difficult to clarify how and why ALS motor neurons are impaired at each clinical stage from disease onset to death, and as a consequence, human autopsy cases alone yield little insight into potential therapies for ALS.

The development of small animal models is of major interest to unravel the etiology, pathogenesis and treatment of neurodegenerative diseases, including ALS. Although animal models cannot replicate human ALS, in order to compensate for the shortcomings of studies using human ALS autopsy samples, researchers must inevitably rely on ALS animal models that can yield very important information for clarifying the pathogenesis of ALS in humans and for the establishment of reliable therapy. Great hopes were put into transgenic mouse models of ALS in which mutant forms of SOD-1 found in familial forms of ALS were over expressed ${ }^{62}$. Of course, human ALS and all ALS animal models share one most important similarity in that both exhibit motor neuron degeneration/death. This important point of similarity has shed much light on the path mechanisms of the motor neuron degeneration/ death at the cellular and molecular levels that would not have been appreciated if only human ALS autopsy samples had been available ${ }^{63}$.

Transgenic mice expressing mutant forms of SOD1 gene serve as models of the familial form of ALS and has been very useful to study the initial mechanisms underlying this neurodegenerative disease. Several hypotheses have been advanced to explain the selective loss of motor neurons such as apoptosis, neurofilament disorganization, oxidative stress, mitochondrial dysfunction, astrogliosis and excitotoxicity. Although disease onset appears at adulthood, recent studies have detected abnormalities during embryonic and postnatal maturation in animal models of ALS.

Murine models of ALS have been useful tools to investigate the effects and mechanisms of drug actions.
At present, the most frequently used model to evaluate candidate drugs is the G93A SOD-1 mouse. Ongoing or planned trials are exploring the value of antiglutamatergic drugs, antioxidants, neurotrophic factors, anti-inflammatory drugs and anti-aggregation drugs.

\section{THERAPEUTIC APPROACHES}

Although amyotrophic lateral sclerosis and its variants are readily recognized by neurologists, about $10 \%$ of patients are misdiagnosed, and delays in diagnosis are common. Prompt diagnosis, sensitive communication of the diagnosis, the involvement of the patient and their family, and a positive care plan are prerequisites for good clinical management ${ }^{64}$.

Treatment starts with an early and efficient diagnosis. In the past, many clinicians believed that there was no reason to make an early diagnosis because there was little to offer the patient with ALS. However, development over the past two decades has changed the way to face ALS. First, an efficient diagnosis evaluation reduces uncertainty for the patient and prevents a long wait for exclusionary tests to be performed. Second, it saves money and time. Third, patients and caregivers benefit from early referral to ALS speciality clinics. Fourth, and most important, there is growing evidence that early intervention can improve and prolong life ${ }^{65,66}$.

\section{Communicating the diagnosis}

Communicating the diagnosis of ALS in an empathetic fashion is a most important and sensitive step in disease management. The information process can not be standardized, which implies that the individual approach is to be preferred. Content and possible modes of delivery information to ALS patients and their families have been constantly reviewed and are only briefly summarized here.

What they already know - With the internet and other medicine information, it is common, in industrial countries, an idea that what some symptoms represent. It is usually best to start by finding out what the patient already knows or suspects and how much more he/she wants to know.

What to tell - Minimal information should include the name and the progressive nature of the disease with an emphasis on positive aspects. Early discussion of prognosis should stress physician-patient relationship. Available therapies, unconventional measures, palliative measures should be mentioned, together with their realistic expectations and known side effects. Current research should be mentioned to foster hope. Information on ALS patient associations is of great importance.

How to tell - Communication should take place in a quiet, private room without interruptions, and in the presence of the family. According to Maguire et al. ${ }^{67}$ three un- 
derlying objectives in the information should be follow: a) do not withhold information if the patient wants it; b) do not impose information if the patient does not want it; $c$ ) gauge and respond to the patient's reaction to the news.

Reinforcement of information - Written material on the disease, a letter summarizing the consultation in lay terms, and/or a tape recording of the conversation is useful.

It may intuitive that initiation of treatment early in the course of ALS, when there are more motor neurons available that may benefit from therapeutic intervention, will be more beneficial than starting treatment a latter time. Treatment is directed to saving the vulnerable neurons.

ALS/MND therapeutics will require juxtaposition in the patient of: Primary treatments to mitigate the underlying pathogenesis of ALS/MND; Adjuvant treatments to stop propagating events trying to maximize survival, strength and function; Symptomatic treatments to minimize symptoms and complications resulting from ALS/MND.

\section{GIVING A TREATMENT}

The complex pathophysiology of ALS presents many potential therapeutic targets, and a number of novel pharmacological agents with varying mechanisms of action have been tested clinically, including agents targeting excitotoxicity, neurotrophic agents, immunomodulators, agents targeting oxidative stress, anti-apoptotic compounds and nutritional supplements. By virtue of the very rapidly developing disease course, ALS is also often regarded as medical condition suited to proof of concept testing for compounds with anti-neurodegenerative potential. Over 500 products have been investigated for neuroprotective effects including those from the categories of free radical scavengers, anti-excitotoxic agents, apoptosis (programmed cell death) inhibitor, anti-inflammatory agents, neurotrophin factor, metal ion chelator, ion channel modulator and gene therapy (Table 13) ${ }^{68,69}$.

Animal drug-screening study in ALS is one of the most important steps to test a potential useful treatment. Almost exclusively the mutant SOD $1^{\mathrm{G} 93 \mathrm{~A}}$ mouse is utilized, permitting identify neuroprotective agents that could mitigate the underlying pathogenesis of ALS/MND.

Although the many candidates were shown to be effective in mice, the ability of this model to predict drug efficacy in humans is ambiguous. Several drugs that prolong survival in animal studies have not shown efficacy in human clinical trials.

\section{THERAPEUTIC TRIALS}

The 1970s saw the beginning of a greater interest in clinical trials for ALS/MND. Clinical trials are imperative to find effective medications for ALS and have significantly evolved over the last decade. New outcome measures have been developed that have reduced the sample size requirement as compared with survival studies. There has been increasing recognition that dose-ranging studies are crucial to full evaluation of experimental agents. While the requirements of late stage trials have not changed, many new designs have been suggested for earlier phase development. While no design achieves the perfect balance of sensitivity and efficiency, clinical trialists continue to work toward the goals of smaller and shorter trials so that more compounds can be studied concurrently ${ }^{70}$.

\section{OUTCOME MEASURES FOR \\ EARLY PHASE CLINICAL TRIALS}

Disease progression has been assessed by different outcome measures, including: Revised ALS Functional Rating Scale (ALSFRS-R), Norris ALS scales, quality of life (Short Form-36 [SF-36]), pulmonary function (forced vital capacity [FVC]) and segmental muscle strength (Medical Research Council [MRC] scale).

As the number of potential neuroprotective agents for ALS increases, the need for early phase trials that screen drugs before proceeding to efficacy trials also grows. However, it is not known which outcome measures perform best and also provide the most meaningful information in brief small trials. To try to assess the performance of different outcome measures for use in early phase clinical trials in ALS, thirty patients underwent six monthly ALSFRS-R), FVC, MRC and quality of life. The ALSFRS-R most strongly predicted survival and provided the most complete data ${ }^{71}$.

The first large multi-center double-blinded, placebo controlled trial took place in the 1990s. Many drug compounds to treat ALS/ MND have been tested but failed. Equivocal results for insulin like growth factor I (IGF-1, Myotrophin $^{\circledR}$ ) were reported in 1990s, one positive and one negative in double-blind, placebo controlled trials. Since them, treatment for ALS has focused in modulation of glutamate toxicity, mitochondrial dysfunction and in the involvement of the immune system in the progress of the disease.

The prerequisites for a successful clinical trial in large phase III efficacy studies are: Drug selection based on disease causes; Agents already tested in ALS animal models or clinical trials; Determination if the drug crosses the human BBB to reach its target ligand, before starting phase Il studies; Determination of the pharmacokinetic profile, the safety/toxicity properties, and the most efficacious dose of the chosen drug in humans, before starting the phase III studies; To identify if the tolerability of a determined dose in patients with ALS is the same of healthy patients and safe; To determine if the frequency of adverse events in patients with ALS is the same of healthy patients and tolerable; Dose-ranging studies are a prerequisite to phase III studies to determine the most effective and safe dosage. 
Table 13. Neuroprotective agents with potential effect on ALS.

$$
\begin{aligned}
& \text { - Antiaggregation } \\
& \text { - Scriptaid } \\
& \text { - Trehalose } \\
& \text { - Anti-apoptosis } \\
& \text { - Activated protein C } \\
& \text { - Calpain inhibitors } \\
& \text { - Caspase inhibitors } \\
& \text { - Minocycline } \\
& \text { - Clusterin } \\
& \text { - DNA binding drugs } \\
& \text { - Lithium } \\
& \text { - Rasagiline } \\
& \text { - TCH } 346
\end{aligned}
$$

- Antiepileptic drugs

- Levetiracetam

- Valproic acid

- Anti-excitotoxicity

- AMPA receptor antagonist

- Memantine

- NBQX

- RPR 119990

- EAAT2 promoter activity

- Ceftriaxone

- Glutamate carboxypeptidase II inhibitor: 2-MPPA

- Glutamate inhibitor

- Riluzole

- Talampanel

- Metabotropic glutamate receptor modulators

- Cannabinoids

- Dexanabinol (HU-211)

- Glutathione

- NMDA NR2B subunit receptor antagonists

- Ifenprodil

- Magnesium

- NAALADase inhibitors

- Anti-inflamation

- Interleukin-1 antagonists

- COX inhibitor

- Celecoxib

- Rofecoxib

- Sulindac

- Protein kinase C inhibitor

- Tamoxifen

\section{- Antioxidants}

- AEOL 10150

- Co-enzime Q10

- Lipoic acid

- N-acetyl-L-cysteine

- Synthetic SOD catalase

- Cell based therapy

- Umbilical cord blood cells

- BM transplant
- Chemotherapy

- Cyclosporine A

- Vincristine

- Cupper chelator

- Trientine

- d-penicillamine

- Gene therapy

- RNAi-based therapy

- Hormones

- Selective estrogen receptor modulators

- Receptor-independent neuroprotective effects of estrogens

- Immunomodulator

- Copaxone/glatiramate

- Thalidomide

- Ion Channel modulators

- Calcium channel blockers

- Nimodipine.

- $\mathrm{Na}^{+}$channel blockers.

- Neuroprotective potassium channel inhibitors

- Mitochondria-targeted

- Arimoclomol

- Glutathione

- Heat shock proteins

- Hyperbaric oxygen therapy

- Omega-3 fatty acids

- Vitamine $\mathrm{E}$

- Neurotrophic factors

- Brain-derived neurotrophic factor (BDNF)

- Ciliary neurotrophic factor (CNTF)

- Fibroblast growth factors (FGF)

- Glial cell line-derived neurotrophic factor (GCDNF)

- Insulin-like growth factor (IGF)

- Nerve growth factor (NGF)

- Neurotrophins (NTF)

- Vascular endothelial growth factor (VEGF)

- Transcranial magnetic stimulation

- Combination therapy

- Drugs

Rofecoxib and creatine

Rasagiline and riluzole

Minocycline, riluzole and nimodipine

- Growth factor and virus

AAV-CT1

AAV-GDNF

AAV-IGF

AVR-GDNF

LV-VEGF

VEGF

AAV: adeno-associated-virus; AVR: Adenovirus;

LV: Lentivirus; BM: bone marrow. 
Besides having a large number of drug candidates that may be neuroprotective in ALS patients, only a small number has been tested at any one time, as recommended criteria. Some drugs showed some efficacy in animal model, but not in humans with ALS (celebrex ${ }^{72,73}$; creatine ${ }^{74,75}$; gabapentin ${ }^{76,77}$; acetylcysteine ${ }^{78,79}$ ). This discrepancy may be due to intraspecies differences (mouse strain, sex, environmental factors), in pharmacokinetics and the difficulty in establishing dose equivalence to achieve the same biologic activity in humans as observed in mice. It may also be that this mouse model of familial ALS does not predict drug effect in patients with sporadic ALS and that development of alternative models should be prioritized.Despite initial positive results in some preclinical and early clinical studies, large-scale clinical trials with different agents have failed to demonstrate a marked effect in patients with ALS / MND. Riluzole is the only one agent that has demonstrated a mild but consistent neuroprotective action.

\section{RILUZOLE}

Riluzole is a benzothiazole derivative that modulates glutamatergic activity, thereby suppressing excitotoxicity. In 1994, the first study of Riluzole (Rilutek $\left.{ }^{\circledR}\right), 50 \mathrm{mg}$, bid, was reported ${ }^{80}$, and the results prolonging patient survival were confirmed in a larger double-blinded, placebocontrolled trial that included North American Centers ${ }^{81-83}$. Great excitement greeted the first positive drug study for ALS. After demonstrating of decline in mortality, Riluzole, most likely related to its anti-excitotoxic properties, was approved by the United States food and Drug Administration in December, 1997. Later meta-analyses indicate that the effect was real, and that there may have been a small effect on function.

ALS/MND is one of few neurodegenerative diseases which have a treatment [riluzole], albeit limited, reputedly directed at the underlying pathogenesis of the disease, that affects the course of survival, rather than merely the symptoms, of the disease process. Although this slowing of progression by a therapeutic intervention may not be large, it represents a breakthrough in the treatment of ALS, not only clinically but also psychologically.

\section{Antioxidant treatment for ALS / MND}

Since the Lou Gehrig, antioxidants have been systematically used in patients with ALS. Although, a systematic review selecting all randomized or quasi-randomized controlled trials of antioxidant treatment for ALS - Cochrane Neuromuscular Disease Group Trials register ( $\mathrm{Au}-$ gust 2005), MEDLINE (January 1966 to August 2005), EMBASE (January 1980 to August 2005) and other sources showed insufficient evidence of efficacy of individual antioxidants, or antioxidants in general, in the treatment of people with ALS. The high tolerance and safety, and relatively low cost of vitamins $C$ and $E$, and other considerations related to the lack of other effective treatments for ALS could explain the continuing use of these vitamins by physicians and people with ALS. While there is no substantial clinical trial evidence to support their clinical use, there is no clear contraindication ${ }^{84}$.

\section{SUPPORTIVE CARE}

The natural course of ALS can be defined as death from respiratory failure. However, life can be extended for many years by artificial ventilation, although death of motor neurons continues, and a patient may become totally paralyzed and be effectively "locked in".

Management of ALS / MND patients can be a day-today struggle. This condition affects every aspect of one's being: physical, emotional, social, financial, and spiritual. Adaptation to loss of function will be ongoing process, requiring continuous revaluation.

Although effective treatment for ALS /MND was not available, the feeling that "nothing can be done" for ALS patients began to change:

- 1975: "Symptomatic care of patients with amyotrophic Lateral Sclerosis "published by Smith and Norris;

- 1980s: "Quality of life" is acknowledged as an integral aspect of patient care;

- 1980s: books devoted to supportive care emerged;

- 1984: "Motor neuron disease: can we do better" is published by Newrick and Langton-Hewer;

- 1985: "Motor neuron disease: toward better care" published by Smith and Norris;

- 1990s: Ongoing clinical research occurred in the areas of speech, swallowing, nutrition, exercise, respiratory care, emotional well being, quality of life, caregiver burden, and health assessment tools: such as ALS functional rating scale (ALSFRS -R), Norris Limb and Bulbar Scale, and Appel Functional Rating Scale;

Multidisciplinary health care teams were identified as the best approach to ALS/MND patient care. In addition, consensus-based approaches to specific patient problems dominated the literature.

Today, there are many specialized clinics in North America, Europe, Oceania and Orient with multidisciplinary teams to guide the patient and family. The clinics provide clinical and emotional care, education, support groups, newsletters, and various other support services. In Brazil, we have seen the same transformation, with the creation of multidisciplinary teams.

Combination of pharmacotherapy and other therapeutic interventions can increase survival, help patients strengthen muscles, improve their ability to perform activities of daily living (ADL) and optimize their quality of life. An understanding of the characteristics of the disease 
and the corresponding treatment modalities is crucial for enhancing the patient's quality of life.

Symptomatic treatments, both pharmacological and non pharmacological, along with alternative therapies can be incorporated into a comprehensive plan of care.

In ALS/MND, the rate of progression is unpredictable. Factors that impact survival can be precipitated by either the patient, the health care professional, and/or the patient's financial resources. Lack of adherence, difficulty in decision making, and ineffectual coping mechanisms by the patient can be a negative impact. The fragmentation of care can be result of inaccessibility to specialized clinics. This along with an inequitable distribution of resources by some governmental agencies, insurance companies, and managed care organization/HMO can lead to poor patient outcomes.

Early identification of problems and symptom management is imperative. Intervention must be timely- often they are too late or unplanned (e.g., emergency ventilation). "Symptom-specific management plays an important part in avoiding costly readmissions for repeat respiratory crisis or injuries from falls. A mechanism for identifying patient problems and monitoring patient outcomes must be put in place in order to enhance ALS care.

One method by which we can achieve these goals is by the development of care pathways. These can reduce the possible error of omission by providing guidelines for assessment, decision making, communication, intervention, and evaluation of patient care.

\section{PRINCIPLES OF ALS / MND MANAGEMENT}

- Patients should make the decisions. It is the care team's responsibility to provide the information in a timely manner;

- The cultural and psychosocial background of the patient and family should be considered;

- ALS care is best delivered by a multidisciplinary team. Most patients do best when they are seen every 3-4 months; however, visits should be scheduled based on rate of disease progression;

- The issue of advanced directives should be raised soon after diagnosis. The team must understand that patients can change their minds and the issue should be revisited every 6 months. Failure to address the issue can precipitate a crisis in which a patient who did not want to artificially ventilated is intubated;

- Psychosocial needs should be addressed throughout the illness. Patients living with ALS face a series of losses and changing needs. Fear of abandonment or dying alone is common. It is important to protect the patient from the loss of self-image and feelings of isolation;

- At each stage of the disease, every effort should be made to encourage patients to live as normal lives as pos- sible, while ensuring that they and their families have access to the comprehensive resources that will allow them to maintain function, as well as access to emotional and spiritual support ${ }^{85}$.

\section{SYMPTOMS TREATMENT}

While ALS is an incurable disease, many symptoms are amenable to supportive and adjunctive therapies, some of which may even improve the disease course.

\section{Weakness}

Patients are usually given an exercise program early in the course of ALS to help delay disability in strong muscles. Exercise entails stretching, strengthening and aerobic exercises. Some studies suggest that the early stages of ALS may be prolonged by moderate exercise. $\mathrm{Pa}$ tients that practiced strengthening exercises using weights three times a week appeared to maintain function and retain quality of life. Eight of the 13 people assigned to the weight training completed the six month study, as did ten of the 14 who did only stretching exercises. Function declined 12 percent less rapidly in the weight training group, and quality of life declined 16 percent less rapidly, according to the investigators working with Dal Bello- $\mathrm{Haas}^{86}$. It is reasonable to begin a strengthening program as soon as possible after the diagnosis in order to maximize the strength of unaffected or mildly affected muscles.

\section{Spasticity}

A systematically review all types of treatments for spasticity in ALS was conducted by Barnham ${ }^{87}$. The Cochrane Neuromuscular Disease Group specialised trials register (searched January 2003), MEDLINE (January 1966 to January 2003), EMBASE (January 1980 to January 2003), CINAHL (January 1982 to January 2003), AMED (January 1985 to January 2003) and LILACS (January 1982 to January 2003) for randomized controlled trials were searched. There were included quasi-randomized or randomized controlled trials of participants with probable or definite ALS revised criteria. Trials of physical therapy, modalities, prescription medications, non-prescription medications, chemical neurolysis, surgical interventions, alternative therapies were included. The primary outcome measure was reduction in spasticity at three months or greater as measured by Ashworth The secondary outcome measures were: validated measures based on history, physical examination, physiological measures, measures of function, measures of quality of life, serious adverse events, and measures of cost. Only one randomized controlled trial that met the inclusion criteria was identified for this review. The included study was a trial of moderate intensity, endurance type exercise versus 'usual activities' in $25 \mathrm{pa}-$ tients with amyotrophic lateral sclerosis. At three months 
patients performing the 15 minute twice daily exercises had significantly less spasticity (mean reduction of 0.43 Ashworth grades versus an increase of 0.25 in controls), as measured by the Ashworth scale. The reviewers concluded that individualized, moderate intensity, endurance type exercises for the trunk and limbs may help to reduce spasticity in motor neuron disease. No other medical, surgical or alternative treatment and therapy had been evaluated in a randomized fashion in this patient population.

\section{DYSARTHRIA}

Dysarthria may occur early in the disease, as a presenting feature, and later become severe in the most of patients. With time, some patients become anarthric. In PBP, dysarthria generally develops prior to dysphagia, with both UMN and LMN degeneration contributing to symptoms. UMN speech tends to be slow and effortful, with poor enunciation and a harsh, strained quality to the voice. LMN in the brainstem may cause slow and effortful speech with breathiness of the voice and slurring of consonants. In some, velopharyngeal incompetence causes air leakage through the nose and lends a hypernasal quality to the voice ${ }^{88}$.

\section{DYSPHAGIA}

The most ALS patients experience some degree of swallowing difficulty at some time during the course of the disease, with progressive worsening. Drooling, dehydration, malnutrition with weight loss and aspiration are all associated with dysphagia.

\section{SIALORRHEA AND THICK PHLEGM}

Based upon data from the ALS Patient Care Database, $50 \%$ of ALS patients report sialorrhea and treatment with anticholinergic medication is ineffective or poorly tolerated in up to $30 \%$ of patients. An alternative treatment in ALS patients with sialorrhea refractory is Botulinum toxin. In a randomized, double-blind, placebo-controlled study of the safety and efficacy of Botulinum Toxin type B (BTXB) for sialorrhea in ALS showed that the injection of $0.1 \mathrm{cc}$ ( $250 \mathrm{U}$ of BTXB) per site at two sites in each parotid gland and $0.15 \mathrm{cc}(750 \mathrm{U})$ per site at two sites in each submandibular gland provided an improvement of $82 \%$ at 2 weeks compared to $38 \%$ receiving placebo. This significant effect was sustained at 4 weeks. At 12 weeks, $50 \%$ of patients receiving BTxb continued to report improvement compared to $14 \%$ receiving placebo. There were no significant adverse events, including dysphagia, in the BTxb group and no significant increase in the rate of decline of vital capacity ${ }^{89}$.

\section{NUTRITION}

Nutrition is an important consideration in the health care for any person and the patient with ALS is no exception. Care should be taken to have a well balanced diet. As ALS progress, difficulties in maintaining good nutrition may be encountered ${ }^{90}$. The following suggestions may be helpful:

- Give enough time to eat. Don't rush;

- Thin liquids are usually the first to give difficulty. Water will "go down the wrong way" more often tomato juice will;

- Softer foods (eggs, mashed potatoes, pasta) require less energy to eat;

- Take smaller bites. Chew and swallow carefully;

- Consider supplementing meals with calorie shakes, or a packaged product, if are not eating enough at mealtimes;

- A daily multivitamin is recommended and adds to good general health, although vitamins and other "health food" formulas will not make ALS better;

- Consider a different method, such as feeding tube, to get food to the stomach if the patient has: No appetite; Too much weight loss; Eating is no longer enjoyable; It takes a long time to eat (more than one hour); Food is "going down the wrong way" daily.

\section{Self-feeding aids}

There are various modifications in eating utensils that make it easier to feed one self. It is very important to check with a rehabilitation or occupational therapist about special devices to assist with self feeding. Product catalogues are available at medical supply stores. Some examples of these modifications include:

- Built-up handles for flatware and utensils are especially useful to people with a weak grasp;

- Plastic cups and glasses are lightweight and easier to hold than glass or china.

\section{Percutaneous endoscopic gastrostomy (PEG)}

PEG in patients with ALS/MND is recommended in patients with difficulty maintaining good nutrition due to pronounced dysphagia. However the timing and the type of gastrostomy tube is not consensual. The MND has suggested that PEG should be done on the following criteria: weight loss of over $10 \%$; severe dysphagia; inadequate energy intake; functional vital capacity of less than $50 \%$ of predicted; history of aspiration and a body mass index of less than 20. Malnutrition is an independent prognostic factor relating to the survival of patients with ALS. PEG can help to solve this problem, even though patients with diminished lung function have an increased mortality after PEG placement. Procedure-related mortality can reach $1.8 \%$, 24 -hour mortality $3.6 \%$ and 30 -day mortality $11.5 \%$. The mean survival rate after intervention is approximately 200 days (185-211 days) $)^{91}$. 
Aggressive proactive nutritional management appears essential in patients with ALS to prevent silent micro aspirations and pneumonia.

\section{RESPIRATORY PROBLEMS}

Shortness of breath or other respiratory symptoms usually occur later in the disease course. Symptoms of respiratory insufficiency include orthopnea, morning headaches and weakness cough. Patients develop dyspnea on exertion, with breathlessness during strenuous and then minor tasks such as eating or talking. Respiratory failure and pulmonary complications of bulbar paralysis (i.e. aspiration pneumonia) are the most common causes of death in ALS.

\section{BRONCHO-PNEUMONIA AND PNEUMONIA}

A retrospective pathological study on a large cohort of patients demonstrated that broncho-pneumonia and pneumonia were the main causes of death (representing $10 \%$ of deaths, that was two times more frequent in bulbar than in spinal ALS), following by heart failure and by pulmonary embolism (representing $6 \%$ of death, exclusively found in spinal onset patients and is related to lower limbs disability). An effort has to be made for a better understanding of the causes of deterioration of ALS patients. A more proactive attitude to treat respiratory infections could have a significant impact on survival ${ }^{92}$.

\section{DYSPNEA}

Chronic alveolar hypoventilation is one of the most important limiting facors in patients with ALS/MND. Like in other patients with chronic alveolar hypoventilation secondary to other neuromuscular diseases (NMD), non invasive ventilation (NIV) has become widely acceptable for ALS patients, as the provision of ventilatory support, providing symptomatic relief and increase life expectance ${ }^{93}$.

While respiratory failure (the major cause of mortality in patients with ALS/MND) is generally a direct consequence of muscle weakness during disease end-stage, a proportion of patients develop early and severe respiratory difficulties during sleep, termed nocturnal hypoventilation. Hypoventilation produces nocturnal hypoxia $(\mathrm{NH})$, which is becoming increasingly recognized as a predictor of survival, independent of respiratory muscle weakness. Patients who had adopted NIV earlier were alive longer than those in whom artificial ventilatory support had been initiated later ${ }^{94}$. Even in ALS/MND patients with symptomatic respiratory failure, it has recently been demonstrated that NIV improves survival ${ }^{95}$.

Patients living longer may be treated at home. When necessary the Home Mechanical Ventilation (HMV) can be applied as non-invasive ventilation (NIV) most often via a facemask, or as invasive ventilation via a tracheostomy.
Generally, the use of NIV is much more prevalent than invasive ventilation in ALS /MND patients. There are many reasons for this, some of which are that NIV is simpler and cheaper to administer and the most patients are ventilated initially during sleep only. Eventually, when the need for HMV exceeds 16-20/24 hours, some centers would consider a change to invasive ventilation.

\section{Diaphragm pacing}

The motor point diaphragm pacing stimulation (DPS) system has become a standardized minimally invasive laparoscopic procedure to maintain and provide natural diaphragm ventilation. A prospective pilot and multicenter pivotal trials of DPS in ALS (20 European centers), analyzing 73 implanted patients, showed that the DPS system can be safely implanted and utilized in ALS patients with a positive effect on diaphragm function. DPS minimizes the impact of Non Invasive Positive Pressure Ventilation on diaphragm dysfunction and positively impacts patients with identified instability of respiratory control $^{96}$.

\section{PAIN}

ALS is usually described as causing painless weakness, but physical pain can be a surprisingly common symptom, affecting $45-64 \%$ of ALS patients. Pain can result from loss of mobility and the instability and the inability to turn in bed, joint contractures or bedsores. In one study, over $50 \%$ of patients reported mild pain and $7 \%$ reported moderate pain at diagnosis, but by 24 months post diagnosis $29 \%$ had severe pain requiring level 3 medication (including opiates). As pain is a predominant feature for a majority of patients its management was identified as an area in need of clarification and guidance for the multidisciplinary team (MDT).

For pain management, the recommendations are:

1. Utilize non-narcotic analgesics, anti-inflammatory drugs, and antispasticity agents for initial treatment of pain in patients with ALS.

2. Administer opioids liberally, following the WHO guidelines, when non-narcotic analgesics fail ${ }^{97}$.

\section{ELIMINATION}

The sphincters that control bowel and bladder function are voluntary muscle that we learned how to control in early childhood. It is rare in ALS to have weakness of these muscles; therefore, ALS patients generally do not become "incontinent." But, getting to the bathroom or getting on and off the toilet can be a problem. An elevated toilet seat makes sitting and rising easier. A handrail on the side of the toilet may provide needed stability. A bedside commode is handy for a person who is very weak. Bedpans are not needed for most ALS patients. 


\section{Bowel function}

The bowel is made of smooth muscle, not voluntary muscle and so the bowel itself is not affected by ALS. However, changes in diet, exercise and fluid intake and weakened abdominal muscles can lead to constipation. It is possible to manage this by:

- Drinking enough liquids (6-8 glasses a day);

- Getting adequate fiber in the diet (bran muffin, breakfast cereal, fruits, fibercon);

- Being as active as possible;

- Serious constipation can lead to bowel impaction, requiring specific treatment;

- Bladder function.

\section{EMOTIONAL LABILITY}

Emotional lability or pseudobulbar affect due to loss of normal inhibition of laughter and crying, complex acts that are thought to depend on neural pathways involved in emotion, respiration, vocalization and facial movements, may also be associated with UMN degeneration.

\section{PSYCHOLOGICAL AND EMOTIONAL ISSUES}

People with ALS differ from those with other terminal illnesses in that they commonly retain capacity for decision making close to death. The role patients would opt to have their families play in decision-making at the end of life may therefore be unique ${ }^{98}$.

Depression is common in ALS, but, if properly managed, psychiatric consultation usually is unnecessary. Occasionally, an overwhelming catastrophic reaction to the disease, stress-induced adjustment problems or marital problems stemming from stress may become serious issues. In these instances, a psychiatry or clinical psychology referral may be necessary.

\section{SPIRITUALITY}

Part of palliative care is tending to the spiritual needs of the dying. Patient's spiritual health affects their decisions about medical care. Those with greater spirituality are more likely to have advance directives, less likely to undergo gastrostomy, less fearful of death and dying, less likely to participate in support groups and more likely to choose a natural death rather than mechanical ventilation $^{99}$. Religion and spirituality ease adaptation and the ability to cope with the process of dying ${ }^{100}$.

Depending upon the severity and/or the frequency of the clinical disturbances, symptomatic medications can provide benefits and improve the quality of life (Table 14) ${ }^{101}$.

\section{PALLIATIVE CARE}

Currently, all of ALS care is palliative. The palliation at the very end of life, when death is near, is a time when specialist care is needed to avoid physical suffering. An- ticipating symptoms before they occur is crucial to proper management. The physician and the patient should share in decision making, understanding that cultural and religious values will have an impact on decisions. The physician should explain the risks and benefits of treatments at each visit in an unbiased way, and understand that the patient's choices could change as the disease progress. As ALS progresses, the goal of patient care changes from maximizing function to providing effective and compassionate palliative care ${ }^{102}$.

\section{COMMUNICATION}

The technological revolution has expanded communication options for people with ALS who cannot rely on natural speech and writing. The assistive technologies are categorized as Augmentative and Alternative Communication (AAC) devices. A systematic review of AAC devices reveals 4 critical variables that are manipulated within clinical and research domains: language representation, output, motor access, and microprocessor units. Language representation has received significant attention for rate enhancement. While most ALS patients spell and rely on typing as a form of input, they can never approach speech production rates; often the slowness of AAC devices reduces their utility. Devices are being designed now that integrate natural language processing and prediction algorithms for word, utterance and even conversational level units as we try to approach natural speaking rates. The output mode has seen advances in speech technology for the storage of digitized voice as well as qualitative improvements to synthetic speech. Voice banking is often considered as an early treatment option, where pALS with intact motor speech skills store their spoken words, phrases, sentences and sounds for future use in customized communication devices. The personalized voice and messages can be used along with standard text-to-speech output to retain the PALS' voice signature. Engineering efforts to customize synthetic speech to the user's own voice through minimal speech sampling is in progress. Speech scientists continue to tackle the gold standard for a device: bad speech in and good speech out, with attention being paid to recognition of dysarthric speech and production of personalized voices (1). Motor access problems are being addressed with visual evoked potentials, detection of alpha and theta waves, and eye gaze recognizers so that head, shoulders, knees and toes are no longer needed. Most devices now offer a range of access methods, starting with keyboards, touch screens, a head mouse, and Morse Code. Finally, microprocessor units are available in every shape and size to meet the needs of the user, from PDAs to laptops made of magnesium-alloy shells, to software that can be downloaded from the Internet and accessed through any home computer ${ }^{103}$. 
Table 14. Symptomatic medications for ALS.

\begin{tabular}{|c|c|c|}
\hline Symptom & Medication & Dosage \\
\hline \multirow[t]{4}{*}{ Anxiety } & Buspirone & 10 mg TID \\
\hline & Diazepam & $5 \mathrm{mg}$ TID \\
\hline & Lorazepam & $0.5-1.0 \mathrm{mg}$ BID \\
\hline & Mirtazapine & 5-30 mg qhs \\
\hline \multirow[t]{5}{*}{ Depression } & Bupropion & 100 mg TID \\
\hline & Mirtazapine & $15-30 \mathrm{mg}$ qhs \\
\hline & SSRI antidepressants & $20-100 \mathrm{mg}$ qd \\
\hline & Tricyclic antidepressant & $20-100 \mathrm{mg}$ qd \\
\hline & Venlafaxine & 37.5-75 mg BID-TID \\
\hline Emotional lability & SSRI & $20-100 \mathrm{mg}$ qd \\
\hline \multirow[t]{4}{*}{ Cramps } & Quinine sulfate & $260-325 \mathrm{mg}$ qd \\
\hline & Vitamin $\mathrm{E}$ & 400 IU TID \\
\hline & Phenytoin & $300 \mathrm{mg}$ qhs \\
\hline & Diazepam & 2-10 mg TID \\
\hline \multirow[t]{7}{*}{ Fatigue } & Amantadine & 100 mg qAM, qnoon \\
\hline & Modafinil & 100-200 mg qAM \\
\hline & Pemoline & $18.75-93.75 \mathrm{mg}$ qd \\
\hline & Bupropion SR & $150-450 \mathrm{mg}$ qd \\
\hline & Fluoxetine & $20-80 \mathrm{mg}$ qd \\
\hline & Venlafaxine & $75-225 \mathrm{mg}$ qd \\
\hline & Pyridostigmine & 60 mg TID \\
\hline \multirow[t]{2}{*}{ Fasciculation } & Gabapentin & 300-600 mg TID \\
\hline & Phenytoin & $300 \mathrm{mg}$ qhs \\
\hline \multirow[t]{7}{*}{ Sialorrhea } & Triciclic antidepressants & 20-100 mg qhs \\
\hline & Atropine sulfate & $0.4 \mathrm{mg} q 4-6$ hours \\
\hline & & 1-2 ophthalmic drops SL q 4-6h \\
\hline & Scopolamine transdermal patch & Transcop TTT - q 7 days \\
\hline & Glycopyrrolate & 1-2 mg TID \\
\hline & Hyoscyamine sulfate & $0.125-0.25 \mathrm{mg} q \mathrm{q}$ hours \\
\hline & Diphenhydramine & $25-50 \mathrm{mg}$ TID \\
\hline \multirow[t]{4}{*}{ Spasticity } & Baclofen & 10-60 mg TID \\
\hline & Dantrolene & 25-100 mg TID \\
\hline & Tizanidine & 2-8 mg QID \\
\hline & Benzodiazepines & $260-325 \mathrm{mg}$ qd \\
\hline \multirow[t]{4}{*}{ Urinary urgency } & Oxybutynin & $2.5-5 \mathrm{mg}$ BID \\
\hline & Amitriptyline & $25-75 \mathrm{mg}$ qhs \\
\hline & Tolterodine & $1-2 \mathrm{mg}$ BID \\
\hline & Oxytrol patches & $3.9 \mathrm{mg}$ qd \\
\hline
\end{tabular}

\section{SEXUALITY AND INTIMACY}

Although ALS has no direct effect on male or female genitalia or fertility, there are many indirect effects. Many commonly used medications can adversely effect erection and orgasm. Weakness and spasticity cause mobility problems, which impair sexual expression. Physical harriers are worsened by fears of injuring the ill partner and guilt about normal desires. Few health care providers raise the issue - either from a lack of comfort in discussing the subject or from a fear that this issue might be perceived as trivial in a disease so serious.

All patients should be asked if they have concerns about sexuality. For example, one could phrase the question as follows:" Many ALS patients have concerns about sexuality. If you have questions, feel free to ask."

ALS poses a great challenge to couples. Pre-existing patterns and problems with communication may be exacerbated. Like other life challenges, the diagnosis offers 
an opportunity for growth and a risk for distance. Of the many challenges patients face, changes in roles within the relationship can be the most painful.

Spouses become caregivers, and it often becomes difficult to maintain the spouse role.

Acknowledge to couples that their relationship roles will change as the illness progress and offer alternatives for support such as clergy counselling, mental health referral, or a sex therapist.

\section{GENETIC COUNSELING}

A DNA-SOD1 or DNA-VAPB tests speeds up the diagnostic process and can be of help in patients with atypical features as well as providing prognostic information. Genetic counseling can be better provided to the patient and relatives. Presymptomatic (predictive) genetic testing should only be performed in first-degree adult blood-relatives of patients with a known SOD1 or VAPB gene mutation. Testing should only be performed on a strictly volunteer basis. Special consideration should be taken before presymptomatic testing is performed in families where the mutation is associated with reduced disease penetrance or with a variable prognosis.

\section{COMPLEMENTARY ALTERNATIVE MEDICINE}

Complementary and Alternative Medicine (CAM) is defined as "a group of diverse medical and health-care systems, practices, and products that are not presently considered to be part of conventional medicine". The use of CAM has increased in recent years. Many individuals with ALS/MND self-prescribe alternative treatments, especially dietary supplements. As health care providers, we have the responsibility to provide our patients with sound information to make informed decisions about treatment modalities and products ${ }^{104}$.

\section{CAREGIVERS}

Caregiver burden is a major issue in ALS, especially when social supports are lacking. Many studies of caregiver needs suggest that there is a predictable pattern of specific needs, and that QoL for caregivers is related to characteristics of the patient's disease, living arrangements and other individual differences. Future studies should examine the relationship of need satisfaction to QoL as well as the potential of caregiver support programs to meet identified needs and improve $\mathrm{QoL}^{105}$.

\section{RECENT LESSONS LEARNED AND PATH FORWARD}

Several therapies have shown promise in preclinical models of motor neuron disease. Several of these treatment approaches, however, failed in human studies. In moving forward with new promising therapies, it is important to first identify whether the past trials were un- successful due to wrong therapy and biological target or because of flaws in trial design and conduct. Better biomarkers of disease and markers of biological activity of the therapies under development are urgently needed. Obtaining information regarding dosage, pharmacokinetics, short-term safety and biological activity in well designed phase I and II studies is critical to the design of phase III trials that will yield meaningful results ${ }^{106}$.

\section{From clinical trials: minocycline}

Considerable laboratory evidence suggested that minocycline possesses anti-apoptotic and anti-inflammatory activity, and may act as a neuroprotective agent. Four published reports showed that minocycline extended survival in the SOD-1 rodent model. The potential neuroprotective effects of minocycline have been examined in models of other neurological conditions and numerous trials are planned to assess whether minocycline may slow the course of human neurodegeneration. A randomized placebo-controlled trial of minocycline was performed at 31 centers in the United States. After a 4 month lead-in phase, 412 patients were randomized to either minocycline in escalating doses up to $400 \mathrm{mg} /$ day, or placebo, for 9 months. Patients underwent monthly evaluations during their 13 months of participation. The outcome measures were ALSFRS-R, FVC, MMT, quality of life (QOL), survival, and safety. The results were not expected. High-dose minocycline has a harmful effect on ALS as measured by the ALS F-R. The ALSFRS-R deteriorated at a $25 \%$ faster rate $(p=0,005)$ in the minocycline group and MMT tended to deteriorate more rapidly in the treated group ${ }^{107}$.

Many apparently effective treatments in open trials (trials lacking a concurrent placebo group) fail in larger double-blind trials, in which neither doctor nor patient knows whether the patient is receiving the study drug. The finding that minocycline has a harmful effect on patients with ALS has implications for trials of minocycline in patients with other neurological disorders, and for how potential neuroprotective agents are screened for use in patients with ALS.

\section{Stem cells explored as als therapy}

Stem-cell transplantation is an attractive strategy for neurological diseases and early successes in animal models of neurodegenerative disease generated optimism about restoring function or delaying degeneration in human beings.

Autologous or allogeneic stem cells, undifferentiated or transdifferentiated and manipulated epigenetically or genetically, could be a candidate source for local or systemic cell-therapies in many diseases. The restricted potential of adult stem cells has been challenged over the past years by reports on their ability to acquire 
new unexpected fates beyond their embryonic lineage (transdifferentiation) $^{108}$.

Bone-marrow has been a source of derived stem cells - The collected cells are cultured it in the lab for about two weeks, before bone-marrow cells have the ability to divide into neural cells with the potential for treating neurological disorders to divide into neural cells.

A potential treatment based on injecting stem cells into the spinal cord - With the lack of effective drug treatments for ALS, and compelling preclinical data, stem-cell research has highlighted this disease as a candidate for stem-cell treatment.

Stem cell therapy is under development as a possible treatment approaching ALS/MND. Italian researchers have performed an exploratory trial in a few ALS patients of using their own stem cells collected from bone marrow as therapy. These stem cells do not appear to differ from those collected from healthy people. The first experiment was presented by Letizia Mazzini at $13^{\text {th }}$ International Symposium on Motor Neurone Disease, in Melbourne, Australia. The autologous bone-marrow-derived stem cells injected into the spinal cord (chest level) of seven ALS patients showed a reasonable margin of clinical safety and maybe some positive results on disease evolution ${ }^{109,110}$. A more recent and similar pilot study of intra spinal injections of mesenchymal stem cells (MSC) has been conducted in 9 ALS patients, demonstrating to be a secure procedure. A possible good effect, with slowly progression, was detected four patients, but the appropriate controls will need to be included in other experiments to see if the treatment does have effect. A new phase 1 study is carried out to verify these data in a larger number of patients ${ }^{111}$.

So far, stem cell treatment trials on ALS patients have demonstrated some short-term beneficial effects, but in the long term the prognosis is not so optimistic.

Human embryonic stem cells - Many scientists say the stem cells derived from embryos have a greater potential for developing into treatments than adult stem cells, but this type of research raises some questions. Opponents of embryonic stem cell (ESC) research consider research using embryonic stem cells unethical and argue that research on adult stem cells is finding cures, too. Some countries prohibit the destruction of the (ESC) for research purposes or restrict the Federal Grants for the Labs that perform research with this type of cell. Besides of the limitations, a team of scientists from the University of Wisconsin-Madison has shown it is possible to rescue the dying neurons characteristic of ALS. A nascent brain cells known as neural progenitor cells derived from human fetal tissue were engineered to secrete a chemical known as glial cell line derived neurotrophic factor (GDNF), an agent that has been shown to protect neurons but that is very difficult to deliver to specific re- gions of the brain. The engineered cells were then implanted in the spinal cords of rats afflicted with a form of ALS. When implanted, "the (GDNF secreting) cells survive beautifully. In 80 percent of the animals, a nice maturing transplants was seen." The implanted cells, in fact, demonstrated an affinity for the areas of the spinal cord where motor neurons were dying. According to Svendsen, the cells migrate to the area of damage where they "just sit and release GDNF." But while the motor neurons exposed to GDNF were protected, the Wisconsin team was unable to detect the connections between the neurons and the muscles they govern. "Even in animals that had lots of motor neurons surviving, we didn't see the (muscle) connection, which explained why we didn't see functional recovery," says Suzuki. "We think the cells are safe, and they do increase the survival of the motor neurons," Svendsen argues. "This may be very important for patients that lose neurons every day. However, it's not a trivial intervention - you have to drill a hole in the spinal cord to get the cells releasing GDNF in. But there are few options for these patients and we will continue to move forward with this approach"112,113.

Different forms of cell transplantation therapy are being tested in models of ALS. While the approach offers hope to patients with ALS, much still needs to be learned in the laboratory before it is ready for human trials. Nevertheless, clinics across the world offer various types of open label cell transplantation therapy for high fees.

Lessons from Beijing

Unproven cell-based treatments for ALS/MND

Olfactory ensheathing glia injections in Beijing: misleading patients with ALS - Hundreds of patients from across the United States, Europe and around the world, including Brazil, have flocked to Beijing, China, where Dr. Huang Hongyun implants olfactory ensheathing glia (OEC) cells in patients with degenerated or traumatic diseases. Dr. Huang Hongyun's explains that OEG cells come from nasal mucosa, which migrates to the olfactory nerve through the cribiform plate to the olfactory bulb. Due to the presence of olfactory ensheathing cells (OEC) the olfactory nerve is known to regenerate throughout adult life. He says that these cells are thought to help nerves repair themselves by releasing growth factors and their amazing healing powers should help patients who cannot be helped with any other modern medicine.

Huang's website includes profiles of patients he has treated for a wide variety of conditions (including ALS as well as well spinal cord injury) and different symptoms, yet Huang treats them all with the same cells. Working at Chaoyang and West Hills (Xishan) hospitals, Huang's team extracts these cells from aborted fetuses and then opens up a hole in the patient's brain or spinal cord, injecting the 
cells. In presentations at scientific conferences, he has said he has helped many patients and has seen no serious side effects. Patients have come forward to say that Huang has helped them, inspiring stories in American and British newspapers about a Chinese doctor who has maybe, just maybe, stumbled upon a modern scientific miracle.

Since 2004, Dr Huang has been invited to explain his work in scientific meetings, but until now, he was not able to draw any conclusions from his research because he had not gathered enough conclusive data.

Evaluations of the patients before-and-after the Beijing procedure, by Dr. Bruce H. Dobkin (medical director of the Neurologic Rehabilitation and Research Program at the University of California, Los Angeles), by Dr. James Guest (Miami Project to Cure Paralysis and the University of Miami Miller School of Medicine), by Dr. Armin Curt (Balgrist) and by Leonard van den Berg (Rudolf Magnus Institute of Neuroscience, University Medical Center Utrecht, Netherlands) showed there were no meaningful improvements in any of the followed patients after the surgery ${ }^{114}$.

Huang's treatment has been considered as part of a seismic shift in alternative therapies. There have always been clinics that cater to desperate patients, offering them unproven, often expensive, treatments. But the boom in stem cell science and the hype surrounding it have brought an explosion of clinics around the world that offer therapies based on living cells. Huang's fees can reach into the tens of thousands of dollars.

The results until now are not just disappointing, they are disturbing. A woman who received an injection into each frontal lobe in Beijing was reported and her ALS progressed at a more rapid rate after the procedure and she suffered disabling side-effects. Clinics that give experimental and potentially harmful treatments outside the construct of well-designed ${ }^{115}$.

\section{Lessons from lithium}

Lithium is a simple chemical substance approved for use in humans and prescribed as a mood stabilizer. In the SOD1 G93A mouse model of ALS, lithium administration results in significant neuroprotection, resulting in delay of disease onset and increased lifespan. In these motor neurons in vitro, lithium has been shown to (1) reactivate the macroautophagy function (through a mechanism of inositol monophosphatase inhibition), (2) remove defective mitochondria and induce mitogenesis, (3) suppress glial cell activation (astrocytosis), which has been implicated in the ALS disease process, (4) decrease $\alpha$-synuclein, ubiquitin, and SOD1 aggregation, (5) suppress glutamatergic excitotoxicity, and (6) possibly induce neurogenesis (in the spinal cord) $)^{116}$.

These experimental results prompted a pilot study by
Fornai et al on the clinical effects of lithium in ALS patients ${ }^{117}$. They conducted a 15-month randomized, parallelgroup trial of 44 adult sporadic ALS patients ( 20 male, 24 female) with duration of disease $<5$ years, most of them with the classic onset, but 11 with the bulbar form. Sixteen subjects were randomized to riluzole $100 \mathrm{mg} /$ day + lithium carbonate $(300 \mathrm{mg} /$ day to $450 \mathrm{mg} /$ day according to lithium concentration's plasma range of $0.4-0.8$ $\mathrm{mEq} / \mathrm{L}$ ) and 28 subjects to riluzole alone. Subjects were assessed at baseline and every 3 months for 15 months. All lithium-treated subjects were alive at the end of the 15month follow-up. In marked contrast, about $30 \%$ of the riluzole-only subjects had died. The data showed that in the lithium-treated subjects, the disease progressed very slowly: the ALSFRS-R and Norris scale drops from baseline were not significant ( $14.3 \%$ and $10.6 \%$, respectively), whereas in the riluzole group the decreases were all significant (39.8\% [p<0.05] and 46.1\% [p<0.01], respectively). Although physical criteria (MRC and FVC) for disease progression were evident in the lithium group, they were significantly lessened compared with the riluzole controls: muscle strength decreased $18.0 \%$ in the lithium group versus $34.8 \%$ in the riluzole-only group; FVC remained significantly higher in the lithium group ( $280 \%$ of baseline) relative to the riluzole group, in which it had fallen to almost $60 \%$ of baseline. Thus, the overall results indicated that lithium significantly delays clinical ALS progression.

The magnitude of these effects (lithium delays progression of ALS) has generated great excitement in the ALS community, increasing the impetus for new research and new treatment strategies. To date no other treatment has shown such a dramatic effect on this fatal disease. However, this was a very small study and the design was problematic: The study did not indicate the criteria for choosing subjects or whether they were consecutive. The placebo group was (unusually) much larger than the activetreatment group, and the number of study completers was not given. Even the causes of death in the control group were not specified. Nor was it a completely blinded study, which raises the question of whether the groups were treated equivalently with respect to possible life-prolonging interventions, ie, bilevel positive air pressure (BiPAP) or percutaneous endoscopic gastrostomy (PEG) tubes.

Due to diagnostic and prognostic variability in persons showing symptoms of ALS, the small numbers in this study were not sufficient to know whether lithium was indeed an effective treatment.

\section{PATIENTS LIKEME}

PatientsLikeMe is a privately funded company dedicated to making a difference in the lives of patients diagnosed with life-changing diseases. The personal experiences with ALS (Lou Gehrig's disease) inspired the found- 
ers to create a community of patients, doctors, and organizations that inspires, informs, and empowers individuals. They are committed to providing patients with access to the tools, information, and experiences that they need to take control of their disease. The more patients that share their information, the more power is possible to detect any important aspect in ALS history.

A collaborative project which was first initiated by Karen Felzer, PhD. and Humberto Macedo, along with all the patients involved in the "Lithium Spreadsheet" who have demonstrated such leadership to this community. All patients were encouraged to have an effective consultation with their doctor to take lithium, to join PatientsLikeMe and share your data with the world. Today, PatientsLikeMe has data on the progression and history of more than 1600 ALS patients - twice the number in the largest ALS trial in history. The results were presented in the last Symposium on ALS / MND, at Birmingham, England. About 250 patients worldwide who had elected to start taking lithium, in collaboration with their doctors, have been tracking their progression and blood levels on PatientslikeMe. No difference has been found on survival, historical forced vital capacity, the ALS Functional Rating scale, and a full symptom battery for most of the patients who have started, as well as for all the other non-lithium users of the system. Contrary to the Italian study, several users presented side effects ${ }^{118}$. Because lithium is a potentially toxic drug, it must be taken under a doctor's supervision with frequent monitoring of blood levels. Common side effects include muscle tremors, twitching, kidney damage, and seizures

In experimental research, Lithium carbonate treatment did not improve the disease progression in two different strains of SOD1 mutant mice ${ }^{119}$.

Besides of these results and considerations, a larger, randomized, controlled and multicentric study of lithium to determine whether the initial findings are truly a new treatment for ALS or the result of chance and small sample size ${ }^{120}$.

\section{FUTURE}

ALS appears now a more complex disease than it did two decades - or even one decade - back, but new insights have been plentiful. Clinical trials should be seen more as experiments on pathogenic mechanisms. More rigorous criteria for moving from cellular and animal models to man should be agreed to avoid time-wasting studies. Ideally, we need to identify biomarkers (EMG studies, CSF analysis, and imaging techniques) that will indicate whether the supposed target has been modified. Understanding of the mechanisms of SOD1 ALS may at last be crystallising into more focused hypotheses, and treatments are being developed to modify this form of disease.

\section{DRUGS}

The involvement of apoptotic mechanisms in the neuronal loss of ALS is one argument that raises the possibility of a final common pathway underlying different neurodegenerative disorders, including ALS, ALS-variants, Alzheimer's disease, Fronto-temporal dementia and Parkinson's disease, and hence a potential for the development of common treatment modalities ${ }^{121}$.

\section{ARIMOCLOMOL}

Arimoclomol is an investigational drug for ALS that amplifies heat shock protein gene expression during cell stress. A preliminary study, including eighty-four participants receiving arimoclomol at one of three oral doses (25, 50, or $100 \mathrm{mg}$ three times daily) or placebo. to assess the safety, tolerability, and pharmacokinetics of arimoclomol in ALS has been finished. The primary outcome measure was safety and tolerability. A subset of 44 participants provided serum and cerebrospinal fluid (CSF) samples for pharmacokinetic analysis. Participants who completed 12 weeks of treatment could enroll in a 6-month open-label study. Arimoclomol at doses up to $300 \mathrm{mg} /$ day was well tolerated and safe. Arimoclomol resulted in dose-linear pharmacologic exposures and the half-life did not change with continued treatment. Arimoclomol CSF levels increased with dose. Arimoclomol was shown to be safe, and it crosses the blood-brain barrier. Serum pharmacokinetic profiles support dosing of three times per day. An efficacy study in ALS is planned ${ }^{122}$.

\section{COMBINATION DRUG SELECTION TRIAL}

A combination of drugs acting on different mechanisms of neurodegeneration may be necessary to reach meaningful outcomes in ALS trials. Moreover, gene expression profiling and genome-wide association studies, together with inhibitory RNA techniques, are helpful for developing new pharmacotherapeutic strategies including gene therapy. It is also likely that the recently advanced generation of induced pluripotent stem cells will lead to the development of cell therapy for $\mathrm{ALS}^{123}$.

Multiple pathways have been implicated in the pathogenesis of ALS. A medication or combination of medications that targets more than one pathogenic pathway may slow disease progression in an additive or synergistic fashion. Such combination therapy has been successful in oncology, though multiple drug interactions and increased incidence of drug side effects should be considered.

Vascular endothelial growth factor (VEGF) receptor-1 and its Ligand VEGF-B

The $60 \mathrm{kDa}$ VEGF-B isoform, VEGF-B(186), is a neuroprotective factor, protecting cultured primary motor neurons against degeneration. When delivered intracere- 
broventricularly, VEGF-B(186) prolonged the survival of mutant SOD1 rats. Compared with a similar dose of VEGF, VEGF-B(186) was safer and did not cause vessel growth or blood-brain barrier leakiness. The neuroprotective activity of VEGF-B, in combination with its negligible angiogenic/ permeability activity, offers attractive opportunities for the treatment of neurodegenerative diseases ${ }^{124}$.

\section{IMMUNOTHERAPY}

Immunotherapy is emerging as a therapeutic approach in neurodegenerative diseases characterized by deposition of aggregated and/or misfolded proteins, including amyotrophic lateral sclerosis (ALS). In familial ALS (fALS1) cases harboring mutations within the gene encoding super oxide dismutase-1 (SOD1), SOD1 aggregates are found in motor neurons and in astrocytes. Although the precise molecular mechanisms of motor neuron degeneration caused by mutant SOD1 remains to be elucidated, it is suggested that toxicity is related to the propensity of the mutant protein to misfold and/or to dissociate from a dimer into a monomer, and ultimately to form aggregates. We have recently developed an antibody that recognizes monomeric/misfolded SOD1 called SOD1-Exposed-Dimer-Interface (SEDI) antibody. This antibody was generated to a peptide sequence corresponding to the dimeric interface of SOD1 (SEDI peptide) and therefore only detects SOD1 when this interface is exposed. Using the SEDI antibody, we have detected the presence of monomeric/misfolded SOD1 in motor neurons of three lines of mutant SOD1 transgenic mice (G93A, G37R and G85R) and fALS cases carrying SOD1mutations. Vaccination of SODIG $37 R$ mice transgenic mice with SEDI peptide or SOD1 aggregates delayed the onset and slowed the progression of disease. Immunization increased life expectancy, improved motor deficits, and reduced motor neuron degeneration. These results suggest that immunotherapy against pathological monomeric/misfolded SOD1 or SOD1 aggregates effectively improves motor and pathological disease outcomes. An immunotherapeutic approach that specifically targets misfolded SOD1 therefore provides promise for development of a novel therapy for the treatment of fALS1 ${ }^{125}$.

\section{IGF-1 - VIRAL DELIVERY}

Adeno-associated virus engineered to contain the gene for IGF-1 (AAV-IGFI) allows targeted delivery of IGF-1 to motor neurons. After IM injection, the gene vector is transported to the neuronal cell body by retrograde axonal transport along motor neurons ${ }^{126}$. AAV-IGF-1 prolongs median survival by $30 \%$ ( 37 days) when administered before disease onset. Human safety, dose schedule, and pharmacokinetics have not yet been established for this novel gene therapy, though AAV-factor IX vector has prov- en safe in patients with hemophilia ${ }^{127}$. A small phase lla trial of AAV-IGF-1 is planned for the near future. Expansion of the viral vector production capacity will be required before proceeding to large scale trials.

\section{EMBRYONIC STEM CELLS AND PROSPECTS FOR THEIR USE IN REGENERATIVE MEDICINE APPROACHES TO MOTOR NEURONE DISEASE}

Human embryonic stem cells are pluripotent cells with the potential to differentiate into any cell type in the presence of appropriate stimulatory factors and environmental cues. Their broad developmental potential has led to valuable insights into the principles of developmental and cell biology and to the proposed use of human embryonic stem cells or their differentiated progeny in regenerative medicine. Stem cell-derived motor neurones could conceivably be used in ALS' patients to replace the degenerated cells, to provide authentic substrates for drug development and screening and for furthering our understanding of disease mechanisms. However, to reliably and accurately culture motor neurones, the complex pathways by which differentiation occurs in vivo must be understood and reiterated in vitro by embryonic stem cells ${ }^{128}$.

The success of cell-replacement therapy in ALS will depend a lot on preclinical evidence, because of the complexity and precision of the pattern of connectivity that needs to be restored in degenerating motor neurons. Stem-cell therapy will need to be used with other drugs or treatments, such as antioxidants and/or infusion of trophic molecules.

\section{FAMILIAL ALS}

There is no specific therapy for patients with a SOD1 gene mutation but a number of projects are underway to develop techniques (RNAi, antisense therapy) to inactivate the mutant SOD1 gene to prevent the synthesis of the cytotoxic mutant SOD1 protein. However, finding a patient to be a carrier of a SOD1 gene mutation can be of advantage to the patient.

ALS Brazilian Association (ABRELA - Associação Brasileira de Esclerose Lateral), founded on 1999, with the aim of attempt to sole the needs of the ALS and other motor neuron disease patients, offers orientation for the patients, their families, caregivers and other health professionals, about the care needs for a best quality of life. More information can be reached at: E-mail: abrela@abrela.org.br Site: www.abrela.org.br - www.tudosobreela.com.br

\section{REFERENCES}

1. Swash M, Desai J. Motor neuron disease: classification and nomenclature. ALS 2000;1:105-112.

2. Schiffman NI, Schiffman MG. The legacy of Lou Gehrig's disease: notable people with ALS. In: Belsh JM, Schiffman PL (Eds). Amyotrophic 
lateral sclerosis: diagnostic and management for the clinician. Armonk, NY: Futura 1996:219-256.

3. Eisen AA. Historical aspects of motor neuron diseases. In: Eisen AA, Shaw PJ (Eds). Handbook of Clinical Neurology. Motor Neuron Disorders and Related Diseases. Elsevier 2007;82:1-12.

4. Lambert EH, Mulder DW. Electromyographic studies in amyotrophic lateral sclerosis. Mayo Clinic Proc 1957;32:441.

5. Subcommittee on Motor Neuron Diseases / Amyotrophic Lateral Sclerosis of the World Federation of Neurology Research Group on Neuromuscular Diseases and the El Escorial "Clinical Limits of Amyotrophic Lateral Sclerosis" Workshop contributors. El Escorial World Federation of Neurology criteria for the diagnosis of amyotrophic lateral sclerosis. J Neurol Sci 1994;124:96-107.

6. World Federation of Neurology Research Group on Neuromuscular Diseases. El Escorial revisited: revised criteria for the diagnosis of amyotrophic lateral dclerosis. HYPERLINK http:// www.wfnals.org/articles/elescorial1998.htm

7. Ross MA, Miller RG, Berchert L, et al. Toward earlier diagnosis of amyotrophic lateral sclerosis. Revised criteria. Neurology 1998;50:768-772.

8. Nodera H, Izumi Y, Kaji R. New diagnostic criteria of ALS: Awaji criteria. Brain and nerve $=$ Shinkei Kenkyu no Shinpo 2007;59:1023-1029.

9. Traynor BJ, Codd MB, Corr B, et al. Clinical features of amyotrophic lateral sclerosis according to the El Escorial and Airlie House diagnostic criteria: a population-based study. Arch Neurol 2000;57:1171-1176.

10. Traynor BJ, Codd MB, Corr B, Forde C, Frost E, Hardiman O. Amyotrophic lateral sclerosis mimic syndromes. A population-based study. Arch Neurol 2000;57:109-113.

11. Rocha AJ, Martins Júnior AC, Nogueira RG, Lederman HM. Magnetic resonance findings in amyotrophic lateral sclerosis using a spin echo magnetization transfer sequence. Arq Neuropsiquiatr 1999;57:912-915.

12. Garcia LN, Silva, AV, Carrete HJr, Fávero, FM, Fontes SV, Monero MT, Oliveira ASB. Relação entre degeneração do trato córtico-espinhal através de ressonância magnética e escala funcional (ALSFRS) em pacientes com esclerose lateral amiotrófica. Arq Neuropsiquiatr 2007;65:869-874.

13. Chieia MAT. Esclerose lateral amiotrófica: considerações a respeito dos critérios diagnósticos. Tese de mestrado em neurociências, Universidade Federal de São Paulo / Escola Paulista de Medicina, 2008.

14. Donaghy M. Classification and clinical features of motor neuron diseases and motor neuropathies in adults. J Neurol 1999;246:331-333.

15. Leigh PN, Swash M, Iwasaki Y, et al. Amyotrophic lateral sclerosis: a consensus viewpoint on designing and implementing a clinical trial. ALS 2004;5:84-98

16. Armon C. Epidemiology of amyotrophic lateral sclerosis/motor neuron disease. In: Shaw PJ, Strong MJ (Eds). Motor neuron disease (Blue Book): Butterworth-Heinemann, Philadelphia 2003:167-205.

17. Dengler R. Current treatment pathways in ALS, a European perspective. Neurology 1999;53(Suppl):S4-S10.

18. Rosen DR, Siddique T, Patterson D, et al. Mutations in $\mathrm{Cu} / \mathrm{Zn}$ super oxide dismutase are associated with familial amyotrophic lateral sclerosis. Nature 1993;362:59-62.

19. Shaw CE, Enayat ZE, Chioza BA, et al. Mutations in all five exons of SOD-1 may cause ALS. Ann Neurol 1998;43:390-394.

20. Andersen P. The genetics of ALS/MND and the role of modifier genes: a clinical perspective. ALS 2007;8:7-8.

21. Veldink JH, Van den Berg L, Wokke JHJ. The future of motor neuron disease. J Neurol 2004;251:491-500.

22. Nihimura AL, Mitne-Neto M, Silva HCA, et al. A mutation in the vesicle-trafficking protein VAPB causes late-onset spinal muscular atrophy and ALS. Am J Human Genet 2004;5:822-831.

23. Andrews J. Amyotrophic lateral sclerosis: clinical management and research update. Curr Neurol Neurosci Rep 2009;9:59-68.

24. Ellison D, Love S, Chimelli L, Harding BN, Lowe J, Vinters HV. Motor neuron disorders. In: Ellison D, Love S, Chimelli L, Harding B, Lowe JS, Vinters H (Eds). Neuropathology: a reference text of CNS pathology, (Ed2) 2004:501-510.

25. Al-Chalabi A, Leigh PN. Recent advances in amyotrophic lateral sclerosis. Curr Opin Neurol 2000;13:397-405.

26. Shaw CE, Al-Chalabi A, Leigh N. Progress in the pathogenesis of amyotrophic lateral sclerosis. Curr Neurol Neurosci Rep 2001;1:69-76.
27. Martin LJ. Neuronal death in amyotrophic lateral sclerosis is apoptosis possible contribution of a programmed cell death mechanism. J Neuropathol Exp Neurol 1999;58:459-471.

28. Sathasivam S, Ince PG, Shaw PJ. Apoptosis in amyotrophic lateral sclerosis: a review of the evidence. Neuropathol Appl Neurobiol 2001:27:257-274.

29. Gonzalez de Aguilar JL, Echaniz-Laguna A, Fergani A, et al.Amyotrophic lateral sclerosis: all roads lead to Rome. J Neurochem 2007;101:1153-1160.

30. CVE - Centro de Vigilância Epidemiológica. Síndrome pós-poliomielite. [Orientações para profissionais de saúde]. São Paulo: SES/SP; 2008. In: ftp:/ / ftp.cve.saude.sp.gov.br/doc_tec/hidrica/doc/SPP08_manual. pdf

31. Sánchez AME, Mejia-Toiber J, Massieu L. Excitotoxic neuronal death and the pathogenesis of Huntington's disease. Arch Med Res 2008;39: 265-276.

32. Ross CA, Poirier MA. Opinion: what is the role of protein aggregation in neurodegeneration? Nat Rev Mol Cell Biol 2005;6:891-898.

33. Tartaglia GG, Cavalli A, Pellarin R, Caflisch A. Prediction of aggregation rate and aggregation-prone segments in polypeptide sequences. Protein Sci 2005;14:2723-2734.

34. Gupta S, Agrawal A, Agrawal S, Su H, Gollapudi S. Immunity Ageing 2006;3:5.

35. Strasser A. The role of BH3-only proteins in the immune system. Nat Rev Immunol 2005;5:189-200.

36. Akhlaq A, Wei-Yi FO, Horrocks L. Neurochemical Aspects of Excitotoxicity. Springer 2008.

37. Appel SH, Engelhardt JI, García J, Stefani E. Immunoglobulins from animal models of motor neuron disease and from human amyotrophic lateral sclerosis patients passively transfer physiological abnormalities to the neuromuscular junction. Proc Natl Acad Sci 1991;88:647-651.

38. Maarten D, Ludo VDB, Robberecht W. Microglia in amyotrophic lateral sclerosis. Acta Neurol Belg 2007;107:63-70.

39. Morahan JM, Yu B, Trent RJ, Pamphlett R. Genetic susceptibility to environmental toxicants in ALS. Amer Genet 2007;144:885-890.

40. Bradley W. New aspects of the cyanobacteria/BMAA hypothesis and future directions. ALS 2008;9:40.

41. Chen A, Montes J, Mitsumoto $\mathrm{H}$. The role of exercise in amyotrophic lateral sclerosis. Physical medicine and rehabilitation. Clin North Amer 2008;19:545-557.

42. Piazza O, Siren AL, Ehrenreich H. Curr Med Res Opinion 2004;20:505-508.

43. Taioli E. All causes mortality in male professional soccer players. Eur J Pub Health, Advance Access published online on April 12, 2007;1-5.

44. Chiò A, Traynor BJ, Swingler R, et al. Amyotrophic lateral sclerosis and soccer: a different epidemiological approach strengthen the previous findings. J Neur Sci 2008;269:187-189.

45. Sutedja NA, Veldink JH, Fischer K, et al. Lifetime occupation, education, smoking, and risk of ALS. Neurology 2007;69:1508-1514.

46. Horner RD, Kamins KG, Feussner JR, et al. Occurrence of amyotrophic lateral sclerosis among Gulf War veterans. Neurology 2003;61:742-749.

47. Chiò A, Logroscino G, Hardiman O, et al. Prognostic factors in ALS: a critical review. ALS 2008;5:1-14.

48. Paillisse C, Lacomblez L, Dib M, Bensimon G, Garcia-Acosta S, Meininger V. ALS 2005;6:37-44.

49. de Carvalho M, Dengler R, Eisen A, et al. Electrodiagnostic criteria for diagnosis of ALS: consensus of an International Symposium sponsored by IFCN. Clin Neurophysiol 2008;119:497-503.

50. Gutierrez J, Zaldivar T, Lara G, et al. Distal vs proximal muscle involvement pattern in patients with early-stage amyotrophic lateral sclerosis. Clin Neurophysiol 2008;119:e125-e125.

51. Carvalho M, Chiò A, Dengler R, Hecht M, Weber M, Swash M. Neurophysiological measures in amyotrophic lateral sclerosis: markers of progression in clinical trials. ALS 2005;6:17-28.

52. Oreja-Guevara C, Rodriguez de Rivera FJ, Alonso Clarke R, AlvarezLinera J, Diez-Tejedor E. Diffusion anisotropy imaging in amyotrophic lateral sclerosis. ALS 2007;8:134.

53. Zetterberg H, Jacobsson J, Rosengren L, Blennow K, Andersen PM. Cerebrospinal fluid neurofilament light levels in amyotrophic lateral sclerosis: impact of SOD1 genotype. Eur J Neur 2007;14:1329-1333.

54. Bowser R, Ryberg H, Wilson M, Darko S, Lacomis D. Protein biomarkers for ALS disease progression. ALS 2008;9:10-11. 
55. Brettschneider J, Mogel H, Lehmensiek V, et al. Proteome analysis of cerebrospinal fluid in amyotrophic lateral sclerosis (ALS). Neurochem 2008;33:2358-2363.

56. Traynor BJ, Codd MB, Corr B, Ford C, Frost E, Hardiman O. Incidence and prevalence of ALS. In: Ireland, 1995-1997: a population-based study. Neurolgy 1999;52:504-509.

57. Srinivasan J, Scala S, Jones HR, Saleh F, Russell JA. Inappropriate surgeries resulting from misdiagnosis of early amyotrophic lateral sclerosis. Muscle Nerve 2006;34:359-360.

58. Chiò A, Mocellini C, Terena A, Schiffer D. Misdiagnosis in ALS: therapeutic and psychological implications. Presented at $5^{\text {th }}$ International Symposium on ALS/MND, Noordwijk, Holland, November, 1994.

59. Belsh JM. Diagnostic challenges in ALS. Neurology 1999;53(Suppl): S26-S30.

60. Bozeat S, Gregory CA, Ralph MAL, Hodges JR. Which neuropsychiatry and behavioral features distinguish frontal and temporal dementia from Alzheimer's disease? J Neurol Neurosurg Psychiatry 2000;68:178-186.

61. Strong MJ. The syndromes of frontotemporal dysfunction in amyotrophic lateral sclerosis. ALS 2008;9:323-338.

62. Deng HX, Siddique T. Transgenic mouse models and human neurodegenerative disorders,Arch Neurol 2000;57:1695-1702.

63. Kato S. Amyotrophic lateral sclerosis models and human neuropathology: similarities and differences. Acta Neuropathol 2008;115:97-114.

64. Radunovic A, Mitsumoto H, Leigh PN. Clinical care of patients with amyotrophic lateral sclerosis. Lancet Neurol 2007;6:913-925.

65. Bromberg M. Accelerating the diagnosis of amyotrophic lateral sclerosis. The Neurologist 1999,5:63-74.

66. Silani V, Borasio D. Honesty and hope: announcement of diagnosis in ALS. Neurology 1999;53(Suppl):S37-S39.

67. Maguire P, Fairburn S, Fletcher C. Consultation skills of young doctors. BMJ 1986;292:1573-1578.

68. Lemmens R, Van den Bosch L, Robberecht W. Therapies in amyotrophic lateral sclerosis: options for the near and far future. In: Eisen AA, Shaw PJ (Eds) Handbook of Clinical Neurology, vol82 ( $3^{\text {rd }}$ series). Motor neuron diseases and related disorders. Elsevier 2007;375-387.

69. Traynor BJ, Brujin L, Conwit R, et al. Neuroprotective agents for clinical trials in ALS: a systematic assessment. Neurology 2006;67:20-27.

70. Shefner JM. Designing clinical trials in amyotrophic lateral sclerosis. Phys Med Rehab Clin North America 2008;19:495-508.

71. Gordon PH, Cheng B, Montes J, Doorish C, Albert SM, Mitsumoto H Outcome measures for early phase clinical trials. ALS 2007;8:270-273.

72. Cudkowicz ME, Shefner JM, Schoenfeld D, et al. Clinical trial of celecoxib in subjects with amyotrophic lateral sclerosis. ALS 2004;5:25-26.

73. Drachman DB, Frank K, Dykes-Hoberg M, et al. Cyclooxygenase 2 inhibition protects motor neurons and prolongs survival in a transgenic mouse model of ALS. Ann Neurol 2002;52:771-778.

74. Klivenyi P, Ferrante RJ, Matthews RT, et al. Neuroprotective effects of creatine in a transgenic animal model of amyotrophic lateral sclerosis. Nat Med 1999;5:347-350.

75. Groeneveld GJ, Veldink JH, Van DTI, et al. A randomized sequential trial of creatine in amyotrophic lateral sclerosis. Ann Neurol 2003;53:437-445.

76. Gurney ME, Cutting FB, Zhai P, et al. Benefit of vitamin E, riluzole, and gabapentin in a transgenic model of familial amyotrophic lateral sclerosis. Ann Neurol 1996;39:147-157.

77. Miller RG, Moore DH, Gelinas DF, et al. Phase III randomized trial of gabapentin in patients with amyotrophic lateral sclerosis. Neurology 2001;56:843-848.

78. Andreassen OA, Dedeoglu A, Klivenyi P, Beal MF, Bush AI. N-acetylL-cysteine improves survival and preserves motor performance in an animal model of familial amyotrophic lateral sclerosis. Neuroreport 2000;11:2491-2493.

79. Kuther G, Struppler A. Therapeutic trial with N-acetylcysteine in amyotrophic lateral sclerosis. Adv Exp Med Biol 1987;209:281-284.

80. Bensimon G, Lacomblez L, Meininger V, and the ALS/Riluzole Study Group. A controlled trial of riluzole in amyotrophic lateral sclerosis. N Engl J Med 1994;330:585-591.

81. Lacomblez L, Bensimon G, Leigh PN, Guillet P, Meininger V. For the amyotrophic lateral sclerosis / Riluzole Study group II. Dose-ranging study for riluzole in amyotrophic lateral sclerosis. Lancet 1996:347:1425-1431.
82. Lacomblez L, Bensimon G, Leigh PN, et al. A confirmatory dose-ranging study of riluzole in ALS. Neurology 1996;47(Suppl):S242-S250.

83. Brooks BR, Sanjak M. Disease-modifying drug therapies. ALS and other motor neuron disorders 2004;5:68-75.

84. Richard OW, Lane Russell JM, Ross M. ALS 2008;9:195-211.

85. Mitsumoto H, Chad DA, Pioro EP. Amyotrophic lateral sclerosis. Contemporary neurology series. Oxford University Press; edition 1; vol.49, 1998.

86. Bello-Haas VD, Florence JM, Kloos AD, et al. A randomized controlled trial of resistance exercise in individuals with ALS. Neurology 2008;71:864-865.

87. Barnham KJ, Masters CL, Bush AI. Neurodegenerative diseases and oxidative stress. Nat Rev Drug Discov 2004;3:205-214.

88. Chiappetta ALML, Oda AL, Oliveira ASB. Doença do neurônio motor. In PROCLIM - Programa de Atualização em Clínica Médica. Artmed (ed), 2005:105-135.

89. Jackson C, Gronseth G, Rosenfeld J, et al. Randomized double-blind study of botulinum toxin type B for sialorrhea in ALS patients. Muscle Nerve 2009;39:137-143.

90. Stanich P, Pereira AML, Chiappetta ALML, Nunes M, Oliveira ASB, Gabbai AA. Suplementação nutricional em pacientes com doença do neurônio motor/ esclerose lateral amiotrófica. Rev Bras Nut Clín 2004;19:70-77.

91. Hartmann S, Van Der Weg B, Binek J, Knoblauch A, Meyenberger C, Weber M. Percutaneous endoscopic gastrostomy in patients with amyotrophic lateral sclerosis: role of BiPAP ventilation. ALS 2007;8:79.

92. Corcia P, Pradat PF, Salachas F, et al. Causes of death in a post-mortem series of ALS patients. ALS 2008;9:59-62.

93. Perrin C, Unterborn JN, D'Ambrosio C, Hill NS. Pulmonary complications of chronic neuromuscular disease and their management. Muscle Nerve 2004;29:5-27.

94. Takada H, Oyama Y, Kon S. Artificial ventilatory management in longterm hospitalized patients with amyotrophic lateral sclerosis at a Japanese Hospital for chronic neuromuscular disoders. ALS 2007;8:85-86.

95. Bourke SC, Tomlinson M, Williams TL, et al. Effects of non-invasive ventilation on survival and quality of life in patients with amyotrophic lateral sclerosis. Lancet Neurol 2006;5:140-147.

96. Onders R, Katirji B, Elmo M, et al. Results of prospective pilot and multi-center pivotal trials of diaphragm pacing in amyotrophic lateral sclerosis: maintaining diaphragm function and improving survival. ALS 2008:9:54-55

97. Miller RG, Rosenberg JA, Gelinas DF, et al. Practice parameter: the care of the patient with amyotrophic lateral sclerosis (an evidence-based review). Report of the quality standards subcommittee of the American Academy of Neurology. Neurology 1999;52:1311-1323.

98. Nolan MT, Hughes M, Narendra DP, et al. When patients lack capacity: the role that patients with terminal diagnoses would choose for their physicians and loved ones in making medical decisions. J Pain Symptom Management 2005;30:342-353.

99. Murphy PL, Albert SM, Weber C, Del Bene ML, Rowland LP. Impact of spirituality and religiousness on outcomes in patients with ALS. Neurology 2000;55:1581-1584.

100. Borasio GD. Meditation and ALS. In: Mitsumoto H, Munsat T (Eds). Amyotrophic lateral sclerosis: a comprehensive guide to management. Demos Medical Publishing, New York, 2001;271-276.

101. Gordon PH, Mitsumoto H. Syntomatic therapy and palliative aspects of clinical care. In: Eisen AA, Shaw PJ (Eds). Handbook of Clinical Neurology. Vol. 82 ( $3^{\text {rd }}$ series) Motor neuron disorders and related diseases. Elsevier, New York, 2007;389-424.

102. Mitsumoto H, Rabkin JG. Palliative care for patients with amyotrophic lateral sclerosis: "prepare for the worst and hope for the best". JAMA 2007;298:207-216.

103. Fried-Oken M, Fox L, Rau M, Tullman J, Baker G, Lou J. Purposes of AAC device use for persons with ALS as reported by caregivers. Augmentative Alternative Communication 2006,20:209-221.

104. National Center for Complementary and Alternative Medicine (NCCAM). What is CAM? NCCAM Publication; No. D347. Available at http:/ / nccam.nih.gov/ health/whatiscam. Updated February 2007.

105. Leirvik A, Liverod M, Holmoy T. Quality of life of patients with amyotrophic lateral sclerosis. Tidsskr Nor Laegeforen 2006;126:2520-2522. 
106. Lanka V, Cudkowicz M. Therapy development for ALS: lessons learned and path forward. ALS 2008;9:131-140.

107. Gordon PH, Moore DH, Miller RG, et al. Efficacy of minocycline in patients with amyotrophic lateral sclerosis: a phase III randomised trial. Lancet Neurol 2007;6:1045-1053.

108. Silani V, Cova L, Corbo M, Ciammola A, Polli E. Stem-cell therapy for amyotrophic lateral sclerosis. Lancet 2004;364:200-202.

109. Mazzini L. Told the 13th International Symposium on Motor Neurone Disease in Melbourne. J Neurosci Res 2002;15;69:908-917.

110. Mazzini L, Fagioli F, Boccaletti R, et al. Stem cell therapy in amyotrophic lateral sclerosis: a methodological approach in humans. ALS 2003;4:158-161.

111. Mazzini L, Mareschi K, Ferrero I, et al. Stem cell treatment in amyotrophic lateral sclerosis. J Neurol Sci 2008;265:78-83.

112. Suzuki M, McHugh J, Tork C, et al. Direct muscle delivery of GDNF with human mesenchymal stem cells improves motor neuron survival and function in a rat model of familial ALS. Molec Therapy 2008;16: 2002-2010.

113. Suzuki M, Svendsen CN. Combining growth factor and stem cell therapy for amyotrophic lateral sclerosis. Trends Neurosci 2008;31:192-198.

114. Van den Berg L. Unproven cell-based treatments for ALS/MND: lessons from Beijing. ALS 2007;8:32.

115. Chew S, Khandji AG, Montes J, Mitsumoto H, Gordon PH. ALS 2007;8:314-316.

116. Fornai F, Longone P, Ferrucci M, et al. Autophagy and ALS: the multiple roles of lithium. Autophagy 2008;4:527-530.

117. Fornai F, Longone P, Lenzi P, et al. Lithium delays progression of ALS. Proc Natl Acad Sci 2008;105:2052-2057.

118. Wicks P, Massagli M, Frost J, Macedo H, Felzer K, Heywood J. A patient-led trial of lithium in ALS using the internet. ALS 2008;9:59.
119. Pizzasegola C, Caroni I, Daleno C, Carrì MT, Bendotti C. Lithium carbonate treatment does not improve the disease progression in two different strains of SOD1 mutant mice. ALS 2008; SW262.

120. Meininger V, Shefner J, Cudkowicz M. Lithium therapy in ALS. ALS 2008;9:122.

121. Waldmeier PC. Prospects for antiapoptotic drug therapy of neurodegenerative diseases. Prog Neuropsychopharmacol Biol Psychiatry 2003; 27:303-321.

122. Cudkowicz ME, Shefner JM, Elizabeth S, et al. Arimoclomol at dosages up to $300 \mathrm{mg} /$ day is well tolerated and safe in amyotrophic lateral sclerosis. Muscle Nerve 2008;38:837-844.

123. Yamamoto M, Fumiaki T, Hiroshi T, Gen S. A strategy for developing effective amyotropic lateral sclerosis pharmacotherapy: from clinical trials to novel pharmacotherapeutic strategies. Expert Opin Pharmacother 2008;9:1845-1857.

124. Koen P, Diether L, Philip VD, et al. Novel role for vascular endothelial growth factor (VEGF) receptor-1 and its Ligand VEGF-B in motor neuron degeneration. J Neurosci 2008;28:10451-10459.

125. Liu HNS, Tjostheim S, Horne P, et al. Immunization strategy for treating amyotrophic lateral sclerosis that targets misfolded SOD1.ALS 2007; 1:150.

126. Kaspar BK, Llado J, Sherkat N, Rothstein JD, Gage FH. Retrograde viral delivery of IGF-1 prolongs survival in a mouse ALS model. Science 2003;301:839-842.

127. Manno CS, Chew AJ, Hutchison S, et al. AAV-mediated factor IX gene transfer to skeletal muscle in patients with severe hemophilia B. Blood 2003;101:2963-2972.

128. Christou YA, Moore HD, Shaw PJ, Monk PN. Embryonic stem cells and prospects for their use in regenerative medicine approaches to motor neurone disease. Neuropathol Appl Neurobiol 2007;33:485-498. 